\title{
Does Equity Analyst Research Lack Rigour and Objectivity? Evidence From Conference Call Questions and Research Notes
}

\author{
Catherine Salzedo ${ }^{\dagger}$, Steven Young ${ }^{\dagger *}$ and Mahmoud El-Haj ${ }^{\dagger}$
}

This version: 1 August 2016

\footnotetext{
${ }^{\dagger}$ Lancaster University Management School. ${ }^{\star}$ School of Computing and Communications, Lancaster University. *Corresponding author: Lancaster University, Lancaster, LA1 4YX; Tel ++44 (0) 1524 594242; Email s.young@lancaster.ac.uk. We are grateful for very helpful comments from two anonymous reviewers whose suggestions significantly improved the paper. Comments and suggestions were also provided by Kathleen Andries, Nathalie Beckers, Robert Bloomfield, Mark Clatworthy (the editor), Simon Dekeyser, Daniel Giamouridis, Tom Guilmet, Katlijn Haesebrouck, Simon Hayley, Gilad Livne, Peter Pope, Richard Taffler, Christophe Van Linden, Sofie Verbieren, and seminar participants at the 2011 British Accounting and Finance Association Doctoral Colloquium, Athens University of Economics and Business, Cass Business School, Exeter University, Katholieke Universiteit Leuven, Lancaster University, and University of Southampton. Financial support was provided by the Economic and Social Research Council (studentship PTA-031-2006-00412 and contracts ES/J012394/1 and ES/K002155/1). A previous version of this paper was circulated under the title "Valuation implications of negative earnings surprises: Evidence from analyst research reports".
} 


\title{
Does Equity Analyst Research Lack Rigour and Objectivity? Evidence From Conference Call Questions and Research Notes
}

\begin{abstract}
Doubts have been raised about the rigour and objectivity of sell-side analysts' research due to institutional structures that promote pro-management behaviour. However, research in psychology stresses the importance of controlling for biases in individuals' inherent cognitive processing behaviour when drawing conclusions about their propensity to undertake careful scientific analysis. Using social cognition theory, we predict that the rigour and objectivity evident in analyst research is more pronounced following unexpected news in general and unexpected bad news in particular. We evaluate this prediction against the null hypothesis that analyst research consistently lacks rigour and objectivity to maintain good relations with management. Using U.S. firm earnings surprises as our conditioning event, we examine the content of analysts' conference call questions and research notes to assess the properties of their research. We find that analysts' notes and conference call questions display material levels of rigour and objectivity when earnings news is unexpectedly positive, and that these characteristics are more pronounced in response to unexpectedly poor earnings news. Results are consistent with analysts' innate cognitive processing response counteracting institutional considerations when attributional search incentives are strong. Exploratory analysis suggests that studying verbal and written outputs provides a more complete picture of analysts' work.
\end{abstract}




\section{Does Equity Analyst Research Lack Rigour and Objectivity? Evidence From Conference Call Questions and Research Notes}

\section{Introduction}

The value of sell-side equity analyst research is a source of ongoing debate among academics, investment professionals, regulators, and the financial media. On the one hand, studies consistently demonstrate that analysts' earnings forecasts, target prices, investment recommendations, and narrative commentaries contain information for investors (Lys and Sohn, 1990; Bradshaw, 2002; Asquith et al., 2005; De Franco and Hope, 2011; Huang et al., 2014). On the other hand, a large body of evidence suggests that the institutional context in which analysts operate renders their research biased, incomplete, excessively dependent on management, reliant on the past repeating itself, and lacking in scientific method (Abarbenall and Bernard, 1992; Fogarty and Rogers, 2005; Kothari et al., 2009; Brown et al., 2015).

Fogarty and Rogers (2005) conjecture that rather than reflecting a neutral and stable expertise that is unaffected by their environment, analysts' work is more accurately characterized by an institutionalized structure where their independence is compromised by financial conflicts of interest and excessive reliance on management as a source of information, and where as a consequence symbolic displays substitute for rigorous scientific analysis. Consistent with an institutional theory interpretation, Fogarty and Rogers (2005) find that analysts' published research lacks rigour and is naïve in the view that past outcomes hold the clues to predicting the future. Asquith et al. (2005) and Huang et al. (2014) confirm that the average analyst report contains little negative commentary about firms or management. Further, Kothari et al. (2009) find no association between the content of analysts' published research and firms' cost of capital, which they attribute to credibility and timeliness problems with sellside research. Collectively, these findings echo doubts expressed by financial journalists, 
investment professionals, and regulators over the rigour and objectivity of analysts' work. ${ }^{1}$

Using insights from psychology that stress the conditional nature of individuals' attributional search processes (e.g., Lau and Russell, 1980) we revisit the view that analyst research lacks rigour and objectivity. In particular, social cognition theory demonstrates that schema-consistent (i.e., expected or predicted) outcomes tend to elicit low levels of penetrating analysis due to their confirmatory nature. Instead, thorough search behaviour aimed at identifying causal factors is more typically reserved for schema-discrepant (i.e., unexpected) events in general, and in particular for unexpectedly negative outcomes that challenge individuals' expectations and existing knowledge structures (Wong and Weiner, 1981). Despite robust evidence regarding the conditional nature of attributional search, studies examining the properties of analyst commentaries typically adopt a random sampling approach designed to maximize generalizability (e.g., Asquith et al., 2005; Fogarty and Rogers, 2005; Kothari et al., 2009; Huang et al., 2014). However, failure to condition on the incentives for attributional search can tilt the evidence toward the conclusion that analyst research lacks scientific rigour since a high fraction of their work is published in response to either good news or no material new information (e.g., Table 1 in Asquith et al., 2005).

We test whether the properties of analyst research vary with the incentives for attributional search as predicted by social cognition theory, with evidence of rigorous, independent financial analysis being more apparent following unexpected bad news. This conjecture is compared against the null hypothesis from institutional theory that analyst research is consistently anodyne, pro-management, and largely symbolic (Fogarty and Rogers, 2005). Our analysis employs a sample of analyst research notes and conference call transcripts

\footnotetext{
${ }^{1}$ For example, Anonymous, 2001. "Shoot All the Analysts", Financial Times, March 20, p.22; Gasparino, C., 2001. "Deals \& Deal Makers: Outlook for Analysts: Skepticism and Blame", Wall Street Journal, June 13, p.C1; Anonymous, 2008. "Titans who were brought to book", Financial Times, March 11, p.2 2008; Cox, A., 2009. "Investment research fighting its corner", Financial Times, March 20, p.15; Grene, S., 2009. "Sellside research hit by quality concerns", Financial Times, June 15, p.3.
} 
for large U.S. non-financial firms over the period from 2004 and 2012. Quarterly earnings announcements serve as our conditioning variable for attributional search behaviour. Valuation theory provides the basis for our measures of rigorous analysis. Specifically, news affects firm value through revisions in either expected future cash flows or discount rates (Penman, 2013). We therefore test whether analysts probe firms' performance prospects (i.e., cash flow expectations) more thoroughly and revise their perceptions of uncertainty (i.e., discount rate expectations) in response to a negative earnings surprise. We also explore the degree of analyst objectivity as measured by their propensity to probe and confront management, with more objective research expected after negative earnings news.

We measure rigorous and objective financial analysis in response to quarterly earnings surprises by applying manual content analysis and natural language processing methods to research notes published within three days of the quarterly earnings announcement and questions posed during the question and answer (Q\&A) segment of the corresponding earnings conference call. Several factors motivate the decision to examine both published research and conference call questions. First, insofar as research notes (conference call questions) are more representative of information dissemination (acquisition) activities, examining both aspects affords a more complete picture of analysts' work. Second, evidence suggests that differences in format (i.e., speech versus text) may affect the observable features of attributional search (Biber, 1986; Linell, 2005: 17-23). In particular, conference call Q\&As are considered to involve more natural, improvised use of language (Frankel et al., 1999; Price et al., 2012; Chen et al., 2013) and as such may yield incremental insights on rigour and objectivity.

Tests control for firm characteristics and operating seasonality that may influence analyst research (Stickel, 1989; Johnson and Zhao, 2012) by comparing the properties of analyst research across negative and non-negative earnings surprises for the same firm-quarter in adjacent years. We select four analyst reports for each earnings surprise. Findings reveal 
statistically and economically higher levels of rigour and objectivity in response to negative earnings surprises. For example, the fraction of conference call questions exploring threats to future cash flows (challenging management) increases by 25 (51) percent following negative earnings news. Similarly, the proportion of negatively-toned outlook (management-related) categories in analyst research notes increases by more than 200 (400) percent following a negative surprise. These findings support the view that analysts engage in analytical, independent research in circumstances conducive to attributional search. We also find evidence of statistically higher levels of uncertainty in analysts' language following negative earnings news, although results are confined to conference call questions and their economic significance is marginal. Further, while non-negative earnings surprises are associated with lower levels of rigour and objectivity, the level of probing analysis is nevertheless material in absolute terms. Collectively our findings suggest that analysts' innate cognitive processing response overrides institutional pressures when attributional search incentives are strong.

Exploratory analysis suggests that conclusions regarding the properties of analysts' work may vary with the type of research examined. On the one hand, challenges to management appear more direct in a conference call environment whereas written research tends to contain more measured commentary. Analysts' propensity to confront management in the absence of bad news is also more evident for conference calls. On the other hand, while the sensitivity of analysts' cognitive processing behaviour to bad news (relative to good news) is significant for both modalities, the effect is more pronounced in written research.

Our analysis contributes to extant research in several ways. First, we extend Fogarty and Rogers (2005) by demonstrating that while analyst behaviour is almost certainly conditioned by institutional context, it also displays features that are entirely consistent with normal attributional search processes. Whereas analysts' work may appear anodyne in schemaconsistent settings, they nevertheless respond with more penetrating research when actual 
performance deviates from expectations generally, and in particular when performance is worse than predicted. Second, we contribute to research on earnings conference calls (Hollander et al., 2010; Matsumoto et al., 2011; Larcker and Zakolyukina, 2012; Mayew and Venkatachalam, 2012; Brochet et al., 2015; Bushee et al., 2015; Davis et al., 2015; Lee, 2016). ${ }^{2}$ Direct evidence on the properties of analysts' questions is sparse and limited to assessments of their pooled predictive ability and response to management tone (Allee and DeAngelis, 2015; Brockman et al., 2015; Chen et al., 2015; Milian and Smith, 2015). Ours is the first study of which we are aware to analyse question-level properties as a means of shedding light on analysts' information acquisition behaviour. ${ }^{3}$ Our analysis therefore responds to calls for more work examining what analysts actually do (Schipper, 1991; Bradshaw, 2011). Third, we compare the properties of analysts' verbal and written research outputs. Huang et al. (2015) is the only other study to the best of our knowledge that compares these modalities. While Huang et al. (2015) test for differences in research themes, we compare the degree of rigour and objectivity associated with the two outputs.

\section{Background, motivation and predictions}

\section{Prior research}

The quality and independence of sell-side analyst research has attracted attention from a range of financial market stakeholders. At the heart of the debate lies concern that the institutional arrangements contextualizing analysts' work lead to a decoupling between the fundamental characteristics of rigorous, independent financial analysis and the inherent

\footnotetext{
${ }^{2}$ Related work examines analyst participation in the Q\&A portion of the call. Findings suggest that participation is determined both by analysts' level of private information and managers' desire to avoid unfavourable questions (Cohen et al. 2013; Mayew et al. 2013).

${ }^{3}$ Matsumoto et al. (2011) examine conference call transcripts and find the Q\&A segment is more informative when performance is poor. However, because their tests aggregate analysts' questions with managers' responses, it is unclear whether this result is due to analysts seeking out more information or management voluntarily disclosing more information. Our evidence speaks directly to analysts' information acquisition activities.
} 
properties of their work (Fogarty and Rogers, 2005). Factors predicted to compromise independence and promote decoupling include analysts' desire to curry favour with management on whom they rely for firm-specific information (Francis and Philbrick, 1993; Chen and Matsumoto, 2006; Barker et al., 2012; Soltes, 2014; Brown et al. 2015), as well as employer incentives to increase investment banking business (Lin and McNichols, 1998; Dechow et al., 2000), maximize trading commissions (Cowen et al., 2006; Gu et al., 2013), provide privileged management access to important investor clients (Green et al. 2014), increase visibility, and demonstrate their superior knowledge to buy-side investors and the public (Groysberg et al., 2011, Barker et al., 2012). Motivated by these concerns, analyst research has been the subject of significant financial media scrutiny and regulatory intervention over the last decade.

Research on the properties of analysts' work yields mixed and inconclusive findings. On the positive side, summary output measures in the form of earnings forecasts, price targets, and investment recommendations contain information for market participants, consistent with analysts undertaking meaningful financial analysis rather than simply rebroadcasting existing information (Bradshaw, 2011). The narrative content of analysts' reports is also incrementally informative (Asquith et al., 2005; De Franco and Hope, 2011; Huang et al., 2014). On the downside, however, research highlights a number of concerns over the quality of their work. First, the economic magnitude of analyst superiority over other forecasting methods appears small (Bradshaw et al., 2012; Altinkilic et al., 2013), suggesting an over-reliance on the past repeating itself (Fogarty and Rogers, 2005; Kothari et al., 2009). Second, analyst forecasts fail to fully and rationally incorporate publicly available information contained in stock prices (Lys and Sohn, 1990; Abarbanell and Bernard, 1992; Clement et al. 2011), accruals (Bradshaw et al., 2001; Drake and Myers, 2011), and accounting conservatism (Louis et al., 2014). Third, analysts display evidence of positive bias toward firms and management: earnings forecasts 
tend to be optimistic (e.g., O'Brien, 1988; Feng and McVay, 2010; Hilary and Hsu, 2013), hold and sell recommendations are relatively scarce (e.g., Womack, 1996; Barber et al., 2006), explicit negative commentary is rare (Asquith et al., 2005; Fogarty and Rogers, 2005), and firms experiencing weak prior performance are associated with the most optimistic earnings forecasts (Abarbanell and Bernard, 1992; Ali et al., 1992; Walther and Willis, 2013). Finally, Kothari et al. (2009) conclude that analyst reports contain little information about risk and uncertainty. These findings cast a cloud over the rigour and objectivity of analysts' work.

\section{The contingent nature of cognitive reasoning}

Social cognition research in the form of attribution theory highlights the circumstances when individuals are motivated to investigate the cause of behaviours and outcomes. Evidence indicates the attribution process is asymmetric with respect to expectations in two ways. First, unexpected events are more likely than expectation-consistent outcomes to elicit causal search because schema-discrepant outcomes cannot be assimilated in individuals' existing knowledge structures (Lau and Russell, 1980; Bohner et al., 1988; Ditto and Lopez, 1992). Second, negative schema-discrepant news is more likely than positive schema-discrepant news to trigger cognitive analysis (Psyzczynski and Greenberg, 1981; Wong and Weiner, 1981). These insights have been used in consumer research to explain how customer dissatisfaction arises and can be managed (Folkes, 1984; Oliver and Bearden, 1985), and in organizational theory to study for example, employee motivation and leadership (Martinko, 1995).

While social cognition theory highlights the conditional nature of attributional search processes, studies examining analyst commentaries often use random or comprehensive sampling techniques that bias against negative schema-discrepant events for several reasons. First, a large fraction of analysts' public research summarizes and interprets existing information in the context of their prevailing investment recommendation. For example, 65 percent of research reports studied by Asquith et al. (2005) are reiterations and 47 percent are 
independent of news. Second, quarterly earnings announcements are the most common news event causing analysts to issue new research (Asquith et al., 2005) but in the majority of cases earnings news is non-negative (Brown and Caylor, 2005). Third, McNichols and O'Brien (1997) predict and find that analysts are more likely to issue research on firms for which they hold favourable beliefs. Insofar as samples of analyst research examined in prior studies are tilted toward schema-consistent or positive schema-discrepant contexts, attribution theory predicts a tendency toward observing anodyne, non-confrontational content due to weak incentives for causal search. Analysts' cognitive reasoning processes therefore serve to reinforce the effect of institutional context on the observable properties of their work.

Negative schema-discrepant outcomes in the form of disappointing earnings news provide a setting where analysts' inherent cognitive processes encourage more rigorous and objective analysis. Social cognition theory predicts that analysts' research activities are more likely characterized by causal search processes resembling objective scientific enquiry when corporate outcomes fall below expectations. We use the sign of the quarterly earnings surprise to differentiate between negative and non-negative schema-discrepant events for the same firm and then compare the characteristics of analysts' work across the two settings. Attribution theory predicts that evidence of rigorous and objective research will be more apparent in response to unexpected news and that this effect will be magnified when the earnings surprise is negative. ${ }^{4}$ Alternatively, if the institutional context in which financial analysis is conducted creates an structure favouring consistently anodyne, pro-management analysis that is overly reliant on the past repeating itself, then one should expect to observe similar (negligible) levels of rigorous, objective analysis across positive and negative surprise partitions.

\footnotetext{
${ }^{4}$ Although studies show that analysts revise key summary outputs in response to earnings surprises (Abarbanell and Bernard, 1992; Yezegel, 2015), this evidence does not speak directly to our research question for two reasons. First, revisions in summary outputs may be driven by factors other than attributional search behaviour (Altinkilic and Hansen, 2009). Second, summary outputs such as earnings forecasts and investment recommendations yield limited and inconsistent insights about analysts' research activities (Schipper, 1991; Bradshaw, 2011).
} 


\section{Operational constructs}

We look to valuation theory for guidance on the properties of rigorous financial analysis (Penman, 2013; Palepu et al., 2013). Valuation theory pinpoints two channels through which news can affect the market's assessment of value. One route is via revision in expected future cash flows. All else equal, negative earnings surprises (NES) can lead to downward revision in expected cash flows as investors extrapolate disappointing short-term earnings performance to previously unknown and potentially persistent operating problems. Attributional search aimed at unpicking the consequences of NES for shareholder value is therefore expected to reflect heightened concern about an entity's prospects, business model and strategic direction compared with schema-consistent or positive schema-discrepant outcomes. Accordingly, rigorous financial analysis in response to NES is expected to demonstrate lower acceptance that past performance is relevant for predicting future earnings and heightened concern about performance prospects. On the other hand, if analysts' natural cognitive reasoning is constrained by institutional structures then their opinion of performance prospects post-NES will be indistinguishable from schema-consistent or positive schemadiscrepant earnings surprises. ${ }^{5}$

The second route through which unfavourable news affects value is via upward revision in discount rate expectations due to an increase in perceived uncertainty (Lui et al. 2007; Brown et al., 2009). Three streams of research support this link (Kothari et al., 2009). First, unfavourable news is expected to increase cash flow risk and hence the discount rate, even when the news does not contain direct information on the risk of those cash flows. Second, $\mathrm{Ng}$ et al. (2009) argue that unfavourable news predicts higher volatility in future earnings. The

\footnotetext{
${ }^{5}$ Analysts may view unexpectedly favourable earnings with particular scepticism, leading to higher levels of attributional search aimed at determining if reported results are persistent. This effect will work against our prediction that analysts focus more on future threats and weaknesses in response to poor earnings news.
} 
increase in uncertainty resulting from higher earnings volatility raises the adverse-selection component of the bid-ask spread and hence the cost of trading the security (Diamond and Verrecchia, 1991; Easley and O’Hara, 2004). Third, the leverage effect also predicts a negative association between news content and cost of capital (Galai and Masulis, 1976; Ball and Kothari, 1989). Based on the view that unfavourable news triggers upward revision in discount rates due to increased uncertainty, rigorous financial investigation by analysts in response to NES should be characterized by higher levels of uncertainty due to enhanced attributional search. Conversely, if analysts fail to respond as theory predicts due to the institutional context in which they operate then their post-NES research will reflect similar levels of uncertainty to that observed for favourable earnings news.

Analyst objectivity toward management is the second dimension of their work on which we seek evidence. NES cause market participants to revise down their perception of management ability (DeFond and Park, 1999; Matsunaga and Park, 2001; Farrell and Whidbee, 2003; Graham et al., 2005; Mergenthaler et al., 2012). ${ }^{6}$ Enhanced cognitive reasoning motivated by NES is therefore expected to increase analysts' tendency to probe, confront or even criticize management. Conversely, if pressure to cultivate and maintain relationships with management renders objective analysis unfeasible then analysts' view on management will be uniformly non-negative regardless of the sign of the earnings surprise.

\section{Unit of analysis}

A novel aspect of this study involves the examination of analysts' written research outputs in the form of published research notes and their verbal interactions with management via the conference call Q\&A. Extant work examining the qualitative aspects of analysts' work

\footnotetext{
${ }^{6} \mathrm{~A}$ decline in management's reputation and perceived competence may also threaten firm value through a higher cost of capital resulting from increased information risk (Barton and Mercer, 2005). We view this potential discount rate effect as part of the overall rise in uncertainty discussed above.
} 
has traditionally focused on published research reports (Previts et al., 1994; Asquith et al., 2005; Fogarty and Rogers, 2005; Kothari et al., 2009; De Franco and Hope, 2011; Huang et al., 2014). Although reports provide an important and visible lens through which to study analyst research, they nevertheless represent only one aspect of their work.

Several factors suggest that published reports may provide an incomplete lens through which to study analyst behaviour. First, while research notes provide evidence on analysts' communication with investors, they provide little direct evidence on how analysts interact with corporate insiders. The Q\&A section of the conference call provides insights into this interaction. Second, analysts' role encompasses both the discovery of new information and the interpretation of publicly available information (Chen et al, 2010; Livnat and Zhang, 2012). While research reports offer a window into analysts' information acquisition and interpretation roles, their ability to cross-examine management directly during conference call Q\&A provides incremental insights into their information gathering activities (Huang et al., 2015). Third, the marketing role of reports coupled with the structured nature of the narrative renders them particularly prone to the characteristics documented by Fogarty and Rogers (2005). Conference calls on the other hand are semi-structured and dynamic (Blau et al., 2015; Davis et al., 2015). Analysts' direct, spontaneous interactions with management may therefore trigger more debate and reveal greater tensions among parties (Chen et al. 2013). Consistent with this view, Brockman et al. (2015) find that managerial tone is less positive in the Q\&A relative to the scripted section of the call, which they attribute to the form and content of analysts' questions. In addition, research in corpus linguistics identifies systematic differences in the properties of written and verbal communication due to factors such as permanence (writing is more permanent than speech) and spontaneity (speech is more spontaneous and less constrained whereas written language is more refined, measured and anonymous) (Biber, 1986; Chafe and 
Tannen, 1987; Linell, 2005). ${ }^{7}$

Motivated by the possibility that direct analyst-manager interaction may yield incremental evidence on analyst behaviour, we extend our focus beyond research reports to include a key information gathering activity. Specifically, we examine both written output in the form of research notes published within three days of a quarterly earnings announcement and the questions posed to management by analysts during the Q\&A segment of the corresponding quarterly earnings conference call. Whether attributional search behaviour differ across these two modalities is an open question on which we seek preliminary evidence.

\section{Research design}

\section{Earnings surprises and within-subject matching procedure}

Tests focus on analyst responses to quarterly earnings surprises, defined as the difference between reported earnings and the market expectation of earnings:

$$
E S_{i q t}=E_{i q t}-E F_{i q t},
$$

where $E S$ is the earnings surprise for firm $i$ in quarter $q$ of fiscal year $t, E$ is quarter $q$ 's unadjusted IBES actual earnings for firm $i$, and $E F$ is the last unadjusted IBES consensus forecast for $q$ prior to the earnings announcement. Negative earnings surprises occur when $E S$ $<0$, whereas $E S \geq 0$ denotes quarters where earnings meet or beat expectations (MBE). ${ }^{8}$

We test for differences in analyst behaviour conditional on the sign of the earnings surprise using the firm as its own control. Specifically, we match a negative surprise announced

\footnotetext{
${ }^{7}$ Contrary to the view that written research is more visible, conference calls may have higher permanence because they are available for web viewing and their contents are transcribed. These features could cause managers to censor their comments during the call. However, research demonstrates that managers who refuse to answer questions or who adhere to scripts during the Q\&A are perceived negatively (Hollander et al., 2010; Lee, 2016), implying that investors value the spontaneity and unexpected content of the Q\&A section.

${ }^{8}$ We focus on the sign of the surprise because social cognition theory offers no clear prediction concerning the impact on attributional search of the magnitude of the earnings surprise, while evidence on the market reaction to NES suggests complex non-linearities (Kinney et al., 2002). Untabulated tests examined whether analysts' response to NES is conditional on the magnitude of the surprise but the results provided no support for an interaction effect.
} 
by firm $i$ in quarter $q$ of fiscal year $t$ with a corresponding MBE announced by the same firm for the same quarter in fiscal year $t-1$. Matching by firm controls for factors such as sector, firm size, business strategy, management team, and accounting methods that shape analysts' research (Johnson and Zhao, 2012), while matching by quarter controls for operating seasonality and variation in analysts' response to earnings news (Stickel, 1989). Using each firm as its own control also helps alleviate endogeneity bias due to management's control over who participates in the call and analysts' pre-announcement investment recommendation.

Conference call transcripts are obtained from Investext and corporate websites. Research notes issued within three days of the earnings announcement are also obtained from Investext. Reports are confined to a three-day publication window to limit the impact of confounding events (De Franco and Hope, 2011). Since firms are tracked by multiple analysts, we select four reports for each NES and MBE announcement, respectively. Analysing multiple reports reduces the risk of analysts with extreme views or conflicted interests skewing our findings and also controls for variation in analyst quality (Hugon and Muslu, 2010). For announcements where more than four research notes are available within the three-day publication window, priority is given to analysts in Institutional Investor magazine's All-American Research Team to maximize the probability of capturing brokers whose views are considered most influential and reliable (Asquith et al., 2005).

\section{Empirical proxies and content analysis methods: conference call questions}

We examine all analysts' questions in the Q\&A segment of the call for the $q^{\text {th }}$ quarterly earnings announcement. Question text is extracted manually and organised by analyst into question blocks. A question block comprises one or more questions posed by analyst $j$ on the same topic. A combination of manual and automated content analysis is then used to identify question blocks that raise concerns about prospects, reflect uncertainty, and challenge 
management. Test variables for the $q^{\text {th }}$ earnings announcement are defined as the fraction of total question blocks relating to the $k^{\text {th }}$ conference call construct:

$$
\text { CC_Construct } k_{k i}=\frac{\text { Number of questionblocks coded for the } k^{\text {th }} \text { construct }}{\text { Total number of questionblocks }} \text {, }
$$

where $k$ equals concern over cash flow prospects $\left(P R O S P \_N E G^{C C}\right)$, revision in discount rate expectations reflected in uncertain language $\left(U N C E R T^{C C}\right)$, and objective analysis reflected in challenges to management (CHALLENGE $\left.{ }^{C C}\right)$.

PROSP_NEG ${ }^{C C}$ is coded using a manual procedure where each question block is classified along the following dimensions: (a) forward-looking, (b) current-period or backwardlooking, (c) strengths and opportunities (SO) facing the entity, and (d) weaknesses and threats (WT) facing the entity. ${ }^{9}$ Examples of SO include margin improvement, cost reduction, brand power, supply chain efficiency, new markets, and planned investments and acquisitions. Examples of WT include margin deterioration, cost inflation, capacity constraints, supply problems, competitive pressure, macroeconomic slowdown, and management turnover. The coding procedure is non-mutually exclusive such that a given question block may be coded simultaneously as forward- and backward-looking, and relating to both SO and WT. Where reference is made to $\mathrm{SO}$ or WT, we also classify tone as positive, neutral or negative. For example, a question block expressing concern about capacity constraints is coded negative WT; a question block exploring whether any capacity constraints exist is coded neutral WT; and a question block speculating on possible improvement in capacity constraints is coded positive WT. We favour manual coding over automated content analysis for $P R O S P \_N E G^{C C}$ because identifying SO and WT, together with the tenor of the discussion, is highly context-specific and sometimes involves reviewing management responses or the presentation section of the call.

\footnotetext{
${ }^{9}$ Negative prospects are distinct from negative tone studied by Chen et al. (2015). Tone applies to backward- and forward-looking discussions whereas prospects are exclusively forward-looking.
} 
We create an indicator variable equal to one for question blocks with forward-looking statements containing negative or neutral discussions of WT, and zero otherwise. From equation (2), PROSP_NEG ${ }^{C C}$ is the number of blocks where this indicator variable equals one scaled by the total number of question blocks. Two members of the research team coded 40 transcripts independently to assess the objectivity and replicability of the coding method. Inter-coder concordance by question averaged 0.90 , which is in line with coding concordances for comparable content analyses (Milne and Adler, 1999; Breton and Taffler, 2001).

From a valuation perspective, greater uncertainty leads to higher discount rates and lower firm value. Accordingly, $U N C E R T^{C C}$ focuses on language demonstrating surprise, confusion, or concern about performance (past, contemporaneous or expected), competitive environment, general market conditions, strategy and business model, and management decisions. Attempts to devise a reliable and replicable manual method to code uncertainty in analyst questions proved difficult because most questions imply a degree of doubt or ambiguity by their nature. To minimize subjectivity and enhance replicability, we use an automated coding method involving a dictionary of uncertainty-related words and phrases based on Loughran and McDonald's (2011) uncertainty wordlist (hereinafter LM uncertainty wordlist). Since the LM uncertainty wordlist is not optimized for verbal Q\&A-style interactions, we supplement this list with a conference call-specific list of uncertainty-related words and phrases as domain-specific wordlists are associated with greater statistical power (Loughran and McDonald, 2011; Henry and Leone, 2016). The supplementary wordlist is constructed using 100 out-of-sample conference call transcripts selected at random over the period 2003 through 2012. Further details of the construction and content of this word list are provided in Appendix Table A1. Following equation (2), $U N C E R T^{C C}$ is equal to the number of question blocks containing at least one element from our uncertainty wordlist, scaled by the total number of question blocks in the call. A limitation of $U N C E R T^{C C}$ is that it does not discriminate unambiguously between 
downside risk, which is the primary focus of our analysis, and upside uncertainty. For example, the statements "I'm trying to figure out how you plan to stop further margin erosion" and "I'm trying to figure out how much additional margin these cost savings will deliver" both contain a phrase from Table A1. The second statement, however, relates to upside uncertainty that is unlikely to trigger an increase in the discount rate. To produce a more refined measure of downside uncertainty we construct an alternative metric that conditions on negative tone. Specifically, we identify question blocks containing at least one element from both our uncertainty wordlist plus one negative word from LM's (2011) negativity word dictionary. Following equation (2), UNCERT_NEG ${ }^{C C}$ is the number of negative-uncertain question blocks, scaled by the total number of question blocks in the call.

Analyst objectivity is measured by the incidence of question blocks that query, probe, confront or even criticize (directly or implicitly) management and their decisions. We use a manual coding procedure to identify blocks that challenge management because such questioning is often contextual and subtle in nature, making it hard to catch using automated methods. (The inter-coder concordance for our manual coding approach is 90 percent.) Following equation (2), CHALLENGE $E^{C C}$ is the number of question blocks classified as challenging management scaled by the total number of question blocks.

\section{Empirical proxies and content analysis methods: research notes}

Research notes require a different coding approach for two reasons. First, customized wordlists developed for coding verbal interactions in conference calls are not applicable for written text. Second, multiple analysts issue research reports in response to a single earnings event. ${ }^{10}$ We therefore construct a representative measure of research note $(R N)$ content by

\footnotetext{
${ }^{10}$ Differences in the approaches used to code research notes and conference call questions means that direct comparisons between analysts' written and verbal responses should be interpreted with caution. We address this issue in a later section by constructing content metrics designed to permit direct comparison across modalities.
} 
coding four reports for the $q^{\text {th }}$ earnings announcement and using the resulting median value:

$$
R N_{-} \text {Construct }_{k}=\text { Median }\left\{k^{\text {th }} \text { construct value computed for } n^{\text {th }} \text { report }\right\}
$$

where $k$ equals negative prospects (PROSP_NEG $\left.G^{R N}\right)$, uncertainty $\left(U N C E R T^{R N}\right)$, and challenges to management $\left(C H A L L E N G E^{R N}\right)$, and $n=1 \ldots 4$.

Manual (automated) content analysis methods are again used to construct measures of concern about prospects and challenges to management (uncertainty). The manual coding procedures for PROSP_NEG ${ }^{R N}$ and $C H A L L E N G E^{R N}$ comprise a two-step process. Stage one involves identifying text blocks relating to corporate prospects (management). A text block comprises one or more sentences, or parts thereof, on the same topic. (Text blocks are not required to be mutually exclusive with respect to prospects and management.) We followed the coding approach in Asquith et al. (2005) to identify text blocks for corporate prospects and management. The method involves specifying a comprehensive set of categories for each dimension. We use forward-looking categories from Asquith et al. (2005) as the basis for our prospects construct. However, since Asquith et al. (2005) code a broad sample of analyst reports, their category list does not capture idiosyncrasies in earnings-related research notes. We therefore identified a supplementary set of categories by examining 100 out-of-sample notes selected at random over the period 2003 through 2012. The combined list of categories used to identify prospects-related text blocks is presented in Appendix Table A2.

A refined version of Asquith et al.'s (2005) template was also used as the basis for identifying management-focused commentary. Broadly, text blocks were identified as containing management-related commentary where the content referred to management directly, contained specific commentary on aspects of firm performance considered to be directly under management's control including managerial execution and strategy, or contained commentary on whether expectations have been met or not. Specific categories used to identify management-related text blocks are presented in Appendix Table A2. 
Stage two involves classifying tone for each category in Appendix Table A2 based on the content of the corresponding text blocks. Three separate tonal classifications are permitted for each category: positive, negative and neutral. The coding method therefore allows us to capture concurrent instances of positive, negative and neutral tone for the same category. Consistent with Asquith et al. (2005), however, each category-tone combination is coded in a binary manner and as a result the method does not capture tone intensity (i.e., multiple text blocks with the same tenor for a given category). We use negative and positive keyword lists from LM (2011) and Schleicher and Walker (2010) as a basis for determining tone, with our manual application permitting contextualization and disambiguation of keywords. For example, the keyword "declining" is negative when used in the context of sales but is positive when used in relation to costs. A conservative approach to coding tone is adopted whereby the default is neutral unless a text block contains a statement that is unambiguously positive or negative. Our prospects (management challenges) metric for the $n^{\text {th }}$ research note is the number of negatively toned categories scaled by the total number of categories in the report. Following equation (3), we define PROSP_NEG ${ }^{R N}$ and CHALLENGE $E^{R N}$ for the $q^{\text {th }}$ earnings surprise as the median of the corresponding four report-level values.

Report uncertainty is coded using an automated procedure similar to that described above for conference calls using LM's uncertainty dictionary. ${ }^{11}$ Report-level uncertainty is the aggregate number of uncertainty-related words scaled by the total number of words in the report. Finally, we define $U N C E R T^{R N}$ for earnings announcement $q$ as the median report-level value computed using the four reports.

\footnotetext{
${ }^{11}$ We do not condition $U N C E R T^{R N}$ on negative tone in our main tests because uncertain language is more unequivocally negative in written format. For example, the sentence "will revenue growth achieve target levels?" in a research note would imply downside uncertainty, whereas the same question posed in a Q\&A setting does not automatically imply downside risk. In supplementary tests described below we construct a conditional measure of uncertainty for research notes. Results are not materially different using this metric.
} 


\section{Sample and data}

The starting point for our sampling procedure is negative quarterly earnings surprises for U.S. nonfinancial firms satisfying the following criteria: (a) at least four research notes available on Investext and issued within three days of quarter $q$ earnings announcement for fiscal year $t$; (b) at least one research note explicitly identifies the announcement as a negative surprise ${ }^{12}$ (c) a non-negative surprise for the same firm-quarter combination is available in year $t-1$; (d) the matching non-negative quarter has at least four analyst reports issued within three days of the corresponding earnings announcement available on Investext; and (e) the corresponding conference call transcripts are available from Investext or firms investor relations webpage. NES quarters are sampled randomly from the resulting population. We sample from the pre-financial crisis period (January 2004 and June 2007) and the financial crisis period (January 2009 and June 2012) to assess the generalizability of our findings to variation in prevailing economic conditions and market sentiment. ${ }^{13}$ The process of coding multiple research notes and conference call transcript for each earnings announcement necessarily restricts sample size. We select 100 negative surprise quarters at random from each sub-period. The final sample therefore comprises 1,600 research notes for $200 \mathrm{NES}-\mathrm{MBE}$ matched pair quarters (i.e., 4×200 NES-related reports plus 4×200 MBE-related reports) and 400 conference call transcripts (i.e., 200 NES calls and 200 matched MBE calls).

The sample is drawn from 45 two-digit SIC categories. Business services (SIC code 73) has the highest representation with 25 firms (13 percent). No other sector accounts for more than 10 percent of the sample. The sample includes research notes published by 64

\footnotetext{
12 An individual analyst may not view an announcement as a negative surprise (a) when the firm achieves the analyst's individual forecast but misses the consensus, (b) where the street consensus differs from the IBES consensus, or (c) where a firm pre-announces disappointing earnings news after the last IBES consensus date.

${ }^{13}$ Our sample window post-dates Regulation Fair Disclosure and rules arising from the Global Analyst Research Settlement to reduce the impact of analyst optimism (Hovakimian and Saenyasiri, 2010). As a consequence our conclusions are silent on the impact of these regulatory changes on the properties of analysts' research.
} 
brokerage firms. JP Morgan has the highest number of reports at 272 (17 percent), followed by Credit Suisse (16 percent), Deutsche Bank (12 percent), and Morgan Stanley (11 percent). Untabulated analyses reveal NES and MBE samples are associated with similar report frequencies for brokerage firms represented in the sample (Pearson correlation equals 0.91).

Our sampling procedure biases toward large, established firms: the median firm has market capitalization of $\$ 7.4$ billion and is followed by 15 analysts. The median conference call takes place on the same day as the earnings announcement and includes 10 analysts whose contributions are classified into 24 distinct question blocks, each comprising approximately 56 words. The median representative research note is published on the same day as the earnings announcement regardless of the sign of the earnings surprise. The length of the median report is similar for negative and positive earnings surprises at 1,541 and 1,507 words excluding boilerplate disclosures, respectively. Table 1 presents descriptive statistics for firm, earnings announcement, and analyst research characteristics partitioned by the sign of the earnings surprise. Evidence that all pairwise differences for NES and MBE firm-level features are statistically indistinguishable from zero confirms that our matching procedure successfully controls for a range of firm-level factors that could influence analysts' response to earnings news. Similarly, no difference between NES and MBE samples is apparent for conference call and research note characteristics. The average market reaction to NES (MBE) is negative (positive) as in prior research. As expected, the NES sample is also associated with a higher likelihood of an earnings loss and lower quarterly earnings growth. These differences highlight the need to control for announcement-level characteristics when comparing analyst responses conditional on the sign of earnings news.

\section{Analysis}

This section tests whether analysts probe cash flow prospects more thoroughly, demonstrate higher levels of uncertainty, and reveal a greater propensity to challenge 
management when earnings disappoint. Table 2 presents univariate (Panel A) and multivariate (Panel B) evidence for performance prospects. Tables 3 and 4 report corresponding evidence for uncertainty and challenges to management, respectively. Univariate analyses employ paired parametric (student t) and nonparametric (Wilcoxon) tests. Multivariate tests control for withinsubject variation in firm- and announcement-level characteristics not captured by our matching method. The vector of control variables includes: natural logarithm of market capitalisation $(\log M V)$ to control for changes in size that could affect the content of analysts' reports; an indicator variable for negative reported earnings (Loss) because losses are likely to attract more negative comments from analysts; forecast dispersion (Forecastdisp) measured as the standard deviation of the last consensus quarterly forecast available on IBES prior to the corresponding quarterly earnings announcement (scaled by lagged share price), because report content may vary with the level of market disagreement; absolute quarterly earnings surprise (|MedianFE|) measured as the absolute value of the difference between IBES quarterly actual earnings and the last IBES quarterly median consensus forecast prior to the earnings announcement (scaled by lagged price), because analysts' views may vary with the magnitude of the earnings surprise; the natural logarithm of analyst following (Log Analyst) as a control for differences in firms' information environment; an indicator variable taking the value of one when the change in seasonally-adjusted quarterly EPS is negative and zero otherwise $(\triangle Q E P S<0)$, because investors penalise negative earnings growth; an indicator variable where firms announce other news concurrent with earnings (OtherInfo) to control for other information that could condition analysts' response to earnings news; and the two-day cumulative abnormal return ending on the earnings announcement date $(C A R)$ as a proxy for market sentiment. Regressions are estimated using Generalized Estimating Equations (GEE) with an exchangeable correlation structure to account for dependency among matched pairs. ${ }^{14}$

\footnotetext{
${ }^{14} \mathrm{GEE}$ and random effects analysis are the two most commonly applied methods for analysing data where repeated
} 
Univariate tests in Panel A of Table 2 show analysts voice relatively more concern about firms' cash flow prospects following negative earnings news. The evidence supports the prediction that schema-discrepant outcomes elicit more attributional search. In the average conference call following a NES, 20 percent of analyst questions refer to forward-looking weaknesses and threats compared with 16 percent when earnings news is neutral or positive. The 25 percent $[(0.20-0.16) / 0.16]$ higher focus on forward-looking problems after NES is statistically and economically significant. Regression results reported in Panel B yield virtually identical conclusions. Similar findings are evident for research notes. The representative research note published in response to non-negative earnings news contains negative-toned comments for 15 percent of outlook categories. The comparable fraction for research notes published after NES is 51 percent, which equates to a 244 percent increase in forward-looking negativity. These conclusions are again robust to multivariate methods reported in Panel B. Collectively, findings presented in Table 2 for prospective analysis are consistent with equity analysts engaging in more rigorous information acquisition and dissemination activity when the incentives for attributional search and cognitive processing are particularly pronounced.

Table 3 documents the impact of earnings news on analyst uncertainty. Findings vary according to the type of research examined and the uncertainty metric used. As expected, conference call results using $U N C E R T^{C C}$ reveal that the majority of questions are characterized by uncertain language irrespective of the sign of the earnings surprise. There is weak statistical evidence that average $U N C E R T^{C C}$ is incrementally higher after NES: the two-tailed probability value for the paired t-test is borderline significant at the 0.1 level in Panel A and the estimated coefficient on NES_D in Panel B is significant at the 0.09 level. However, univariate conclusions in Panel A are not robust to nonparametric methods and the economic magnitude

\footnotetext{
measurements for an individual or firm are correlated. GEE provides unbiased estimates of regression coefficients and variances without needing to specify the correct covariance structure (Hardin and Hilbe, 2003; Twisk, 2004). Choice of specific working correlation structure for GEE estimation is irrelevant for matched pairs data because all non-identity structures produce the same result (Liang and Zeger, 1986).
} 
of the difference is small (less than two percent). Results for $U N C E R T \_N E G^{C C}$ provide more robust evidence that conference call questions display heightened downside uncertainty after NES. Univariate tests in Panel A reveal that five percent $[(0.49-0.465) / 0.465]$ more questions are associated with downside uncertainty in the average conference call following negative earnings news, and that this difference is significant at the 0.1 level or better. Regressions reported in Panel B yield virtually identical results. Although uncertainty-related effects are statistically and economically less pronounced than those reported in Table 2 for cash flow prospects (possibly because uncertain language is an endemic feature of analyst conference call language), the evidence in Table 3 is nevertheless consistent with analysts facing greater uncertainty following events that trigger attributional search and cognitive processing. Tests conducted using analyst research notes on the other hand, reveal no evidence of statistically higher levels of uncertainty following NES. The median representative research note contains only one uncertainty-related word per 1,000 regardless of the sign of the earnings surprise. The absence of uncertainty-related content in response to earnings surprises generally and NES in particular is consistent with Kothari et al.'s (2009) evidence and suggests that rigorous information dissemination via analyst research notes in response to earnings news is confined to cash flow prospects. Alternatively, these null results may reflect the inability of our empirical construct to measure analyst uncertainty with sufficient accuracy.

Analyst objectivity is assessed by their propensity to challenge management. Results in Table 4 reveal analysts are more likely to challenge management when earnings disappoint. Univariate tests conducted using conference call data indicate that on average analysts challenge management in 14 percent of questions posed during calls held after NES, compared with nine percent of questions in response to non-negative earnings results. Findings support the view that analysts increase their objective information gathering behaviour when doubts arise about the effectiveness of management's control over operational and strategic aspects of the 
business. The 51 percent $[(0.142-0.094) / 0.094]$ increase in analyst willingness to confront management after a NES is economically and statistically significant, and in line with attribution theory which predicts more intense causal search activity when outcomes disappoint. Results reported in Panel B reveal these conclusions are robust to multivariate methods. Similar findings are also apparent for published research notes. Whereas only four percent of management-related discussions are negatively toned in the representative report following non-negative earnings news, the mean fraction rises to 20 percent post-NES. ${ }^{15}$ The 400 percent $[(0.197-0.038) / 0.038]$ increase in unfavourable commentary demonstrates analysts' readiness to challenge management in their written research outputs produced in circumstances conducive to attributional search. The statistical significance and economic magnitude of this increase is confirmed by the regressions reported in Panel B. Collectively, findings presented in Table 4 provide robust evidence that analyst research activities display material objectivity when the incentives for attributional search and cognitive processing are sufficiently strong.

Evidence that the properties of analyst research vary according to the sign of the earnings surprise is consistent with social cognition theory which predicts higher (lower) levels of rigorous, objective analysis in response to negative (positive) schema-discrepant events. ${ }^{16}$ Note, however, that evidence consistent with rigour and objectivity is not confined exclusively to NES related research outputs. Results reported in Tables 2-4 demonstrate non-trivial levels of independent, scientific analysis in response to non-negative earnings surprises. For example, 16 percent of questions posed by analysts during conference calls following non-negative earnings surprises raise concern about prospects, nine percent challenge management, and 47 percent of questions are characterized by downside uncertainty. Similarly, the representative research note published in response to non-negative earnings news includes negatively-toned

\footnotetext{
${ }^{15}$ Results for research notes display skewness: the median percent of management-related discussions that are negatively toned in the representative report is zero for both surprise partitions.

${ }^{16}$ The majority of non-negative earnings surprises are positive schema-discrepant: 93.5 percent (94 percent) of the MBE sample are positive based on the mean (median) consensus forecast.
} 
comments for 15 percent of outlook categories. These findings cast further doubt on claims that analyst research systematically lacks rigour and objectivity. Instead, evidence that (i) nonnegative schema-discrepant events are associated with material levels of rigorous, objective research and (ii) such properties are more apparent following negative schema-discrepant news supports the view that equity analysts engage in meaningful financial analysis in circumstances when the motives for attributional search are present.

We conducted a series of further tests to assess the robustness of findings reported in Tables 2-4. First, we used regression methods suggested by Cram et al. (2009) as alternatives to GEE for matched-pair data. Results and conclusions were unaffected. Second, we employed alternative definitions of performance prospects, uncertainty and challenges to management with no material change to our results and conclusions. We also confirmed that results hold in different economic and financial regimes: coefficient estimates on $D \_N E S$ in Tables 2-4 do not vary significantly across the pre-crisis (2004-2007) and crisis (2009-2012) periods.

\section{Preliminary evidence on properties of verbal and written research}

This section reports comparative evidence on the properties of analysts' research across conference calls and research notes. Clear predictions regarding the precise nature of potential differences are hard to establish due to offsetting effects as described in more detail below. Accordingly, the following analysis is best viewed as exploratory and should interpreted with this caveat in mind. We compare conference calls and research notes on the basis of three attributional search characteristics. ${ }^{17}$ The first feature is directness, which reflects the level of candour displayed by analysts when discussing prospects and management decisions. The second feature is prevalence, measured for each modality as the fraction of analysts displaying

\footnotetext{
${ }^{17}$ Our research design also creates interpretational problems. Ideally we would have compared comments for the same analyst across alternative modalities. Unfortunately, this is not possible because many conference call transcripts published before 2008 do not identify analysts by name.
} 
attributional search behaviour. The third feature is sensitivity, measured as the difference in prevalence between good and bad news events.

Insofar as speech is associated with more candour than text due to greater spontaneity and perceptions of lower permanence (Chafe and Tannen, 1987; Linell, 2005), conference calls are expected to be associated with more aggressive commentary as analysts cross-examine managers. The information gathering (dissemination) nature of conference calls (research notes) may also cause analysts to adopt a more (less) adversarial approach toward management. Conditional on attributional search activity occurring, analysts are expected to be more direct in their views of firm performance and managerial decisions during the conference call Q\&A to obtain the information they require. On the other hand, the personal aspect of verbal interactions may accentuate the institutional forces described by Fogarty and Rogers (2005), resulting in less direct attributional search behaviour during conference calls. We examine directness qualitatively by comparing examples of challenges to management across the two modalities. We focus on cases where analysts challenge management because the level of directness and variation therein is likely to be particularly prominent in such circumstances. The process of identifying examples involved first isolating all challenges to management for each modality. All such instances were then reviewed and the most aggressive cases identified based on a qualitative assessment.

Representative examples of analysts' challenges to management are included in Appendix Table A3. Several findings are apparent. First, the data reveal unequivocal evidence of direct challenges to management decisions and firm performance by analysts regardless of modality: examples illustrate how (at least some) analysts are more than ready to confront management when circumstances dictate, and that such confrontations can be direct and uncompromising. Second, the data suggest a higher level of directness for analyst verbal interactions with management, as demonstrated by phrases such as "total breakdown", "awfully 
perplexed", "reject it out of hand", "cannot make that reconcile", "how believable is that", "whose fault" and "confused and disappointed". While research notes also contain clear (and in some cases stinging) criticism of management, the linguistic tone tends to be less vivid and emotive, with phrases such as "overpromised", "not helped”, "scarce visibility”, “consistently underestimated" and "too aggressive" more the norm. The evidence provides qualitative support for the view that interactive Q\&A sessions with management yield more direct evidence of analyst objectivity than written reports.

Next we explore whether the prevalence of attributional search varies between conference calls and research notes. Our prevalence measure for research notes (conference calls) is the fraction of analysts demonstrating at least one case of attributional search behaviour in their written commentary (questions to management). ${ }^{18}$ Since our sampling approach limits research reports to four per firm-announcement, we construct a comparable conference call measure based on questions posed by four analysts selected at random from each call. Given the weak findings reported above for uncertainty, evidence of attributional search behaviour is defined as challenging management and expressing concern about performance prospects.

We offer no directional prediction for prevalence due to potentially off-setting effects. On the one hand, because the same viewpoint or piece of information is often disseminated (rebroadcast) by multiple analysts in their individual research notes, attributional search behaviour may be evident in a high fraction of analysts' published research outputs. In contrast, analysts are less likely to repeat the same question posed by one of their colleagues during a conference call and therefore the fraction of analysts explicitly demonstrating attributional search may

\footnotetext{
${ }^{18}$ An important caveat associated with this approach is that by constructing a metric that is more comparable across modalities we risk compromising statistical power gained from using format-specific metrics that reflect fundamental differences in content and style. If the reduction in power affects these outputs differentially, then observed variation in relative strength will be driven by statistical biases rather than fundamentals. An alternative way of comparing effects is to compute standardized regression coefficients for regression models in Table 2-4. Unfortunately, interpreting standardized coefficients for indicator variables such as $D \_N E S$ is problematic because a one standard deviation change is not meaningful for binary variables.
} 
appear lower. On the other hand, lower perceived permanence and visibility of direct verbal interactions relative to written commentaries could result in a higher prevalence of attributional search for conference call questions.

Table 5 compares the fraction of analysts probing forward-looking weaknesses (Panel A) and challenging management (Panel B) in their research notes and conference call questions. Findings in Panel A reveal that the fraction of analysts expressing doubts over prospects in their research reports exceeds the comparable fraction for conference call questions, and this difference is apparent regardless of the sign of the earnings surprise (probability values $>0.01$ for two tailed tests). The higher prevalence of attributional search activity for research notes is consistent with the dissemination and re-broadcasting features of written research outweighing the competing effects for speech.

Findings for challenges to management reported in Panel B display a different pattern. Absent bad news, challenges are more likely in a conference call setting: the fraction of analysts challenging management in their research notes is zero for the median non-negative earnings surprise compared with 17 percent in the corresponding call. Results are consistent with the direct, spontaneous nature of speech yielding a more powerful setting in which to observe analysts confronting management when the incentives for attributional search are relatively weak. In contrast, the median fraction of analysts challenging management in response to negative news converges for written and spoken modalities at 25 percent, while the mean prevalence of challenges is economically and statistically higher for research notes. Conditional on bad news, the dissemination attribute of written research appears to offset (or even dominate) the effects for speech. Collectively, these findings suggest that conclusions about the properties of analyst research may depend on a potentially complex interplay between the motives for cognitive processing and the type of output examined.

The final two rows in Table 5 report evidence on the sensitivity of attributional search 
behaviour, measured as the change in prevalence associated with a move from non-negative to negative news. While the sensitivity of cognitive processing to bad news is statistically and economically significant for both modalities, difference-in-differences tests show the relative increase is more pronounced for research notes (two-tailed probability values $<0.01$ ). For example, the mean fraction of analysts raising doubts about prospects in Panel A increases by 64 percent from 0.51 after a positive surprise to 0.84 for research notes after a negative surprise. The corresponding mean increase for conference calls is 20 percent $[(0.40-0.34) / 0.34]$. Similar results are evident in Panel B for analysts' propensity to challenge management.

The exploratory evidence reported in this section suggests that conclusions about the properties of analyst research can vary according to the particular form of research examined. Results suggest that exclusive focus on a single modality is unlikely to provide a complete picture of the work analysts undertake. While direct comparisons of written and verbal channels raise non-trivial research design issues, findings suggest structural differences in the observable properties of analysts' research that warrants further investigation.

\section{Conclusions}

Behavioural psychology demonstrates that individuals' propensity to undertake rigorous analysis is contingent on the context in which their cognitive reasoning is studied. We use insights from the cognitive processing literature to shed new light on the properties of sell-side analyst research and in particular on the debate over whether their work lacks rigour and objectivity. Specifically, we test whether the degree of rigour and objectivity varies with analyst incentives for attributional search, with higher levels of both features predicted to be more evident in response to negative schema-discrepant events. This conditional view of analyst research is evaluated against the null hypothesis that their work reflects an institutionalized structure in which symbolic displays consistently replace rigorous scientific analysis (Fogarty and Rogers, 2005; Kothari et al., 2009). In a departure from prior research, we seek evidence 
on the properties of analysts' work using written research notes and direct verbal interactions with management during the Q\&A portion of conference calls.

Consistent with predictions, analysts are more likely to challenge management and explore concerns about future performance when quarterly earnings fall short of expectations. Findings apply to both research notes published within three days of the earnings announcement and questions posed by analysts during the corresponding earnings conference call. Analysts also display statistically higher levels of uncertainty in their conference call questions following disappointing earnings news, although economic significance is marginal. While negative schema-discrepant news is associated with enhanced levels of attributional search, non-trivial levels of rigour and objectivity are nevertheless evident in response to non-negative schemadiscrepant earnings news. Evidence that analysts challenge management and explore threats to future performance even when earnings news is non-negative further demonstrates the need to condition conclusions regarding the properties of analyst research on schema-discrepant events, as predicted by attribution theory. Collectively, our findings are inconsistent with claims that analyst research lacks rigour and objectivity due to the institutional context in which they operate. Instead, findings suggest that analysts' innate cognitive processing response outweighs institutional considerations when attributional search incentives are strong.

Results also suggest that structural differences in the observable aspects of analysts' work with respect to format (e.g., speech versus text) and aims (e.g., information acquisition versus information dissemination) could affect conclusions regarding attributional search behaviour. First, evidence that negative earnings surprises lead to enhanced attributional search as measured by higher levels of uncertainty is restricted to tests using conference call data. Our failure to document higher levels of uncertainty in analysts' research notes supports Kothari et al.'s (2009) conclusion that analysts' published research provides little meaningful information about firm risk. Second, qualitative comparisons suggest that analyst criticism of management 
tends to be more blunt and outspoken in a conference call environment, whereas their written research tends to contain more reserved commentary. Analysts' propensity to challenge management in the absence of bad news is also more evident during conference calls. Third, while the sensitivity of analysts' cognitive response to bad news (relative to good news) is statistically and economically significant for both forms of research, the effect is more pronounced for research notes.

Several caveats apply to the analysis. The generalizability of our findings is constrained by the small sample size and our emphasis on large U.S. firms. The pairwise matching approach is also unlikely to resolve all endogeneity concerns associated with conference call questions and as such we cannot rule out the possibility that findings are confounded by selection bias. We also acknowledge that comparisons between the properties of conference call questions and research notes are preliminary and that findings should be interpreted with caution. Despite these concerns, however, results suggest several avenues for future research. First, detailed analysis of the interplay between managers and analysts in the Q\&A section of the conference call merits further work. For example, understanding why analysts pose the questions they do, how answers inform their research, and how much information analysts glean from their peers' questions has the potential to provide new insights on analysts role as information intermediaries. Second, our exploratory comparison of conference calls and research notes, together with concurrent work by Huang et al. (2015), highlights the benefits and opportunities associated with studying analysts' work through multiple lenses. Examining different information gathering and dissemination channels may also shed light on the process by which analysts transform the mosaic of soft information on strategy, risk, management quality, etc. into valuations and investment recommendations. Finally, identifying factors in addition to the sign of the earnings surprise that affect the properties of analysts' work (and the form such effects take) will further improve our understanding of what analysts do and how they do it. 


\section{Appendix Table A1: Supplementary wordlist used to measure uncertainty in analysts' conference call questions}

\begin{tabular}{|c|c|c|c|}
\hline want to be $<0$ : $1>$ clear* & how do you think & fair to say & are $\langle 0$ : $1>$ seeing \\
\hline trying to figure out & when do you expect & apparently & meaningless \\
\hline $\operatorname{I'm}<0: 1>$ trying & how do you expect & I'm $<0$ : $1>$ curious & more specific \\
\hline trying to & can you $<0: 1>$ clarify & just curious & but \\
\hline give $\langle 0: 1>$ a sense & clarification & just a curious thing & yet \\
\hline get $\langle 0: 2\rangle$ a sense & more clarity & does that mean & hedg* \\
\hline get $a /$ the $\langle 0: 1\rangle$ sense & greater clarity & do you $<0$ : $1>$ think & when was the last time \\
\hline make sense & more transparency & or & what was the last time \\
\hline don't have $<0: 2>$ sense & greater transparency & change & better idea \\
\hline ecipher & spell out & how long & do you think \\
\hline could $\langle 1: 1\rangle$ go through & is that what you're saying & probabt* & bottleneck* \\
\hline want to make sure & suggest & possibt* & help \\
\hline how should & suggesting & potentially & sustainab* \\
\hline how do & imply & maybe & how much \\
\hline give $<0: 1>$ a/the feel $*$ & implying & might & any view \\
\hline do you $<0: 2>$ feel $^{*}$ & is there & make sure & suddenly \\
\hline you suggest* & it sound* & risk* $^{*}$ & hesitant \\
\hline are $\langle 0: 1>$ saying & it seem* & uncertain* & how should $\langle 1: 1\rangle$ expect \\
\hline a handle & it appear* & perhaps & how should $<1: 1>$ think \\
\hline should we & looks like & be clear & issues \\
\hline should I & normally & unclear & problems \\
\hline as $\langle 0: 1>$ underst* & in the past & quantify & are you saying \\
\hline what $<0$ : $1>$ underst* & unusual* & visibility & competition \\
\hline make sure $<0: 1>$ underst* & abnormal* & what progress & how long \\
\hline is that fair & surpris* & next steps & anticipate \\
\hline does that mean & shock* & more specific & would you say \\
\hline wonder* & how typical & parameters & shake out \\
\hline where are & unsustain* & details & anticipate \\
\hline what's $<0: 1>$ happen* & all of a sudden & color & would you say \\
\hline what might have happened & is it possible & range & remind \\
\hline any idea & it $\langle 0: 1\rangle$ looks & cannibalize & price war \\
\hline how should $\langle 1: 1>$ look at & it $\langle 0: 1\rangle$ seems & pressure & walk $<0: 1>$ through \\
\hline how quickly & I $<0: 1>$ think & impair & flavour / flavor \\
\hline hould we $<0: 1>$ expect* & I believe & write-off & delve \\
\hline should $\mathrm{I}<0: 1>$ expect* & seemingly & write-down & retention \\
\hline what happens if & seems like* & inventory & scenario \\
\hline there $\langle 0: 1>$ sense & sounds like & capacity & envis* \\
\hline is there $\langle 1: 1\rangle$ else & do you believe & different & historically \\
\hline ow should $<0: 1>$ look at & do you think & outlook & moving parts \\
\hline $\mathrm{e}<0: 1>$ assuming & where do you think & erratic & timeframe \\
\hline$r<0: 2>$ to assume & does that mean & volatil* & trajectory \\
\hline d you assume & does it appear & expose & I thought \\
\hline when do you think & the impression & exposure & we thought \\
\hline
\end{tabular}

Words and phrases are extracted from 100 out-of-sample conference call transcripts selected at random during the period 2003 through 2012. Each transcript was read and questions demonstrating surprise, confusion, concern, lack of understanding, and significant doubt were isolated. Characteristic words and phrases common to these isolated questions were then identified, where commonness was defined as occurring in at least half of selected questions. The wordlist is implemented using a flexible search algorithm that stems words with numerous variants and allows for minor variation in phrase structure. Stemmed words in the above table are identified with an asterisk $(*)$. Flexible phrase structures allow for variation in intermediate words and are represented above by the generic $\langle\mathrm{x}: \mathrm{y}\rangle$ structure, where $\mathrm{x}(\mathrm{y})$ is the minimum (maximum) number of intervening words permitted in a given phrase. We combine the above list with LM's uncertainty wordlist (removing duplicates) and use a java script to count incidences of words and phrases. 
Appendix Table A2: Categories used in manual coding of research notes to construct measures of concern about performance prospects and challenges to management

\begin{tabular}{|c|c|c|c|}
\hline \multicolumn{2}{|l|}{ Prospects } & \multicolumn{2}{|l|}{ Management } \\
\hline Categories & Source & Categories & Source \\
\hline Business outlook & Asquith et al. & Management (incl. credibility) & Asquith et al. \\
\hline Competitive outlook & Asquith et al. & Cost cutting & Asquith et al. \\
\hline Customer numbers outlook & Asquith et al. & $\mathrm{M} \& \mathrm{~A}$ & Asquith et al. \\
\hline Demand outlook & Supplementary & Strategy & Supplementary \\
\hline Future excess capacity & Supplementary & Restructuring & Supplementary \\
\hline Market share & Supplementary & Advertising & Supplementary \\
\hline Pricing outlook & Supplementary & Pricing strategy & Supplementary \\
\hline Regulatory outlook & Supplementary & Personnel strategy & Supplementary \\
\hline Other future & Supplementary & Forecast credibility & Supplementary \\
\hline Debt rating* & Asquith et al. & Earnings targets & Supplementary \\
\hline Law suits* & Asquith et al. & Analyst view & Supplementary \\
\hline New financing* & Asquith et al. & Reference to "CEO”, “CFO”, & \\
\hline New products & Asquith et al. & "managers", "management", or & \\
\hline Other prospective ${ }^{*}$ & Asquith et al. & reference to named individual(s) & Supplementary \\
\hline Expense outlook & Supplementary & Commentary on whether & Asquith et al. \\
\hline Cash flow outlook & Supplementary & expectations have been met & \\
\hline Margin outlook & Supplementary & & \\
\hline Profitability outlook & Supplementary & & \\
\hline Revenue outlook & Asquith et al. & & \\
\hline Growth prospects & Asquith et al. & & \\
\hline Future investments & Asquith et al. & & \\
\hline Future capx. & Supplementary & & \\
\hline Margin expectations & Supplementary & & \\
\hline Valuation & Supplementary & & \\
\hline Investment rationale & Supplementary & & \\
\hline Price movements & Supplementary & & \\
\hline Future buybacks & Asquith et al. & & \\
\hline International opportunities outlook & Asquith et al. & & \\
\hline Earnings or revenue visibility & Supplementary & & \\
\hline Insufficient capacity & Supplementary & & \\
\hline Tax rate outlook & Supplementary & & \\
\hline Recommendation & Asquith et al. & & \\
\hline Price target & Supplementary & & \\
\hline Industry outlook & Asquith et al. & & \\
\hline Economic outlook & Supplementary & & \\
\hline
\end{tabular}

Forward-looking categories from Asquith et al. (2005) form the basis for coding the prospects construct, supplemented by categories specific to earnings-related research notes (Supplementary) identified by examining 100 out-of-sample notes selected at random over the period 2003 through 2012. (Categories marked with * were not part of Asquith et al.'s main coding criteria but were included in an additional category where the researchers collected data on whether there was additional information announcements relating to these specific issues occurring within + or -4 days of the issue date of the report coded.) Categories used to code the challenges to management construct capture three aspects of management-related commentary: categories from Asquith et al. (2005) regarding aspects of firm performance considered to be directly under management's control (Asquith et al.); direct references to management (Supplementary); and commentary on whether expectations have been met (Supplementary). Text blocks are manually assigned to categories on a non-mutually exclusive basis. 
Let me ask I guess a high-level question about what happened in this quarter. There was an investor event where you seemed to signal that there was weakness in early May and then you went out of your way to say that things were fine. You reported a number that I think some would argue warranted a preannouncement. The issues you've pointed to seem like they shouldn't have been surprising. ... Many are going to say that there was a total breakdown in communication and that, at best, you lack visibility on your businesses. There has been a series of missteps here. How do investors regain confidence in this team and that you've finally got the outlook right? (Life Technologies conference call on 28.07.2011)

Nice results. I don't think this is going to be an unexpected question but I'm a little bit more than surprised that the joint venture reached outside of the organization to the point where you actually went to a completely different organization to recruit a CEO. And I'm at a loss as to why that was even put on the table or even considered Let alone actually pulling the trigger and hiring somebody. (Sempra Energy conference call on 05.05.2009)

You just didn't, you just didn't update us that you had changed it to include retroactivity for the $3 \mathrm{Q}$ also at that period, at that point. So, this is the first time that I am hearing in a public forum that the low end of your guidance range assumed retroactivity for the 3Q. This is the first time... But you didn't tell us that. You did not tell us that the low end of the guidance range assumed retroactivity for the $3 \mathrm{Q} \ldots$ I mean, as an analyst community we are trying to assess how you performed versus where you had thought you would perform. And so, I am not sure how we make that leap. (Centene Corp conference call on 08.02.2008)

To whom do you ascribe the blame for the disconnect. You complained earlier about the Street not understanding. So whose fault is that? Is that the Street's fault or is that a communication gap? (Cephalon conference call on 15.02.2005)

During the quarter there was some discussion that in fact the Dow had made a takeover bid on DuPont and I guess the question is, how did your board handle this? The stock obviously has not been a good performer in recent years and
The U.K. was also a disappointment as heavy promotion for soup and beans was supposed to drive top line. The CEO blamed poor consumer insights by U.K. management in product restaging, but Joe Jiminez was supposed to be the rising star in management especially post the departure of Neil Harrison. And now the head of Asia has also left. Consistency. Management crowed about its success in North America, which is deserved. But as so often happens, the strengths HNZ has in one area are inevitably offset elsewhere. (Credit Suisse research note on Heinz, 31.01.2005)

Management seems quite proud that they are gaining market share and again mentioned acquisitions as one of the three growth legs. However, results last year and in this quarter point to much more rapid deterioration in gross margin than they or we anticipated. For this stock to work, we believe management needs to convince the Street that margins can be sustained at levels that justify the current investment levels. This quarter did not help build the confidence to that goal. (Credit Suisse research note on Best Buy, 31.05.2007)

What is clear is that Centene once again overpromised on EPS for 2007, as it did in 2006. We are concerned that the new 2008 EPS guidance could also prove challenging to achieve. We reduce our price target... Conference call provides little help in clarifying 4Q07 results and '08 outlook... We left the call with many unanswered questions on the composition of the 4Q results and the anticipated drivers of the 2008 EPS guidance. This was not helped by the company limiting the call to only 30 minutes. (Deutsche Bank research note on Centene Corp, 31.12.2007)

Dean's “cost savings" strategy has not worked. Dean's strategy is to create a competitively advantaged cost structure that will either force smaller players to cede market share to Dean or exit the industry altogether. So far neither has happened. If the strategy does work, it will require expensive investments by Dean to get there with scarce visibility of how the savings drop to the bottom line. (Credit Suisse research note on Dean Foods Company, 30.09.2010)

We believe that the pressure is on the company to take active steps to create shareholder value in light of the underperformance of Dow's stock under the current management team and the continued strong cash flow generation. 


\section{Appendix Table A3 Continued}

looks like maybe you just reject it out of hand something that could have added a lot to shareholder value. (DuPont conference call on 24.07.2007)

I have to turn back to Avastin on the commercial side. I'm really just awfully perplexed by the answer I think to the first question regarding the sector. It was there were really no changes, I think you said, in the inventory channel for Avastin. I an just kind of looking at penetration rates here. So basically on a relative basis, your penetration rate in the front line grew I think around 38 percent, and it looks like it grew around 9 percent even in the relapse setting. So you're looking at strong growth, especially on that front line setting, around 38 percent, and yet you have sequential reported sales growth around 9 percent. I just cannot make that reconcile. (Genentech conference call on 10.01.2005)

I have to make a comment first and I will do the dirty work. Bill, a lot has changed since Tony left. But this kind of does bring memories of Tony back with this tax rate rabbit out of your hat and that's kind of my comment... But I think you have to tell us when you knew this tax rate benefit was there. Was it in your prior guidance. Because I think to say you are on track really kind of I think is not really accurate. (Heinz Company conference call on 28.02.2005)

I guess I am not going to congratulate you for Las Vegas, but I guess someone should mention that at least you kind of figured out the problem and dealt with it rapidly. So I commend you for that. The second question is - I am a little confused and disappointed that the share repurchase in the quarter was zero and we haven't been very aggressive buying back stock... I would like to understand why you're not repurchasing shares. And if necessary I would like to take this to the Board level to understand that decision. (Pulte Homes conference call on 26.10.2004)

Again I know you can't detail it, but for a $\$ 36$ million restructuring in Cranes to get $\$ 50$ million that quickly, I'm just trying to get my arms around it, how believable is that?... And then I would also ask the second question, why didn't we want to do this earlier? (Terex Corp conference call on 21.07.2011)

\section{(HSBC Global Research research note on Dow Chemical Co, 30.09.2007)}

GR seemingly went out of its way to bring down the 2006 consensus estimate of $\$ 2.53$. Rather than providing new guidance, the Company warned the investment community that there are a number of "uncontrollable" overhead related costs that could rise sharply in $2006 \ldots$...Frankly, we were disappointed and somewhat surprised by management's announcement. On the one hand, we realize that GR has had an annual tendency to "reset" expectations. However, we were hoping managemen would take necessary steps to offset any looming headwinds. After all, pension costs, FX and compensation expense are risks that should have been anticipated earlier this year... Hopefully, GR will attract more value investors who will_urge management to focus on cost reduction rather than an emphasis on market share. We believe this change in focus is imperative. (Bear Stearns research note on Goodrich Corp, 30.09.2005)

Despite deteriorating fundamental trends and investor scepticism, management still sees 2008 E EPS $+4.7 \%$ on implied flattish shipments. Despite clear signs over the past several years that the domestic business was entering the relative maturity stage of the corporate lifecycle, management has consistently underestimated the impact of both increased seasonality and cyclicality on its economic model. (Credit Suisse note on Harley Davidson, 31.12.2007)

We agree that CA requires dramatic change in the structure of the sales organization, but we can't help but question the path chosen in this case given the results along with the historical record. At the same time, we can't help but question the timing of this move, just before the transition of leadership to a new CEO, who presumably will have his or her own opinions as to the right direction to take. (JP Morgan research note on CA Technologies, 27.07.2012

This is not the first time LIFE/IVGN miscommunicated/lacked visibility/was too aggressive. One quarter makes not a trend, but several quarters/years do. A core component of buying any stock has to be management confidence; the magnitude of, and explanation of this miss has to place LIFE in the penalty box. (Cowen research note on Life Technologies, 30.06.2011)

This table presents examples of analyst directness, as reflected in use of vivid and uncompromising language when challenging management about firm performance and decision taken. The process of identifying examples of directness involved first isolating all challenges to management for each output type (conference call questions and research notes). All such instances were then reviewed and the most aggressive cases identified based on the authors' qualitative assessment. 


\section{References}

Abarbanell, J., \& Bernard, B. (1992). Tests of analysts' overreaction/underreaction to earnings information as an explanation for anomalous stock price behavior. The Journal of Finance, 47 (3), 1181-1207

Abraham, S, \& Cox, P. (2007). Analysing the determinants of narrative risk information in UK FTSE 100 annual reports. British Accounting Review, 39 (3), 227-248.

Ali, A., Klein, A., \& Rosenfeld, J. (1992). Analysts' use of information about permanent and transitory earnings components in forecasting annual EPS. The Accounting Review, 67 (1), 183-198.

Allee, K. \& DeAngelis, M. (2015). The structure of voluntary disclosure narratives: evidence from tone dispersion. Journal of Accounting Research, 53 (2) 241-274

Altinkilic, O., Hansen, R. (2009). On the information role of stock recommendation revisions. Journal of Accounting and Economics, 48 (1), 17-36

Altinkilic, O., Balashov, V., \& Hansen, R. (2013). Are analysts' forecasts informative to the general public? Management Science, 59 (11), 2550-2565

Asquith, P., Mikhail, M., \& Au, A. (2005). Information content of equity analyst reports. Journal of Financial Economics, 75 (2), 245-282.

Ball, R., \& Kothari, S. (1989). Nonstationary expected returns: Implications for tests of market efficiency and serial correlation in returns. Journal of Financial Economics, 25 (1), 51-74

Barber, B., Lehavy, R., McNichols, M., \& Trueman, B. (2006). Buys, holds, and sells: the distribution of investment banks' stock ratings and the implications for the profitability of analysts' recommendations. Journal of Accounting and Economics, 41 (1), 87-117.

Barker, R., Hendry, J., Roberts, J., \& Sanderson, P. (2012). Can company-fund managers meetings convey informational benefits? Exploring the rationalisation of equity investment decision making by UK fund managers. Accounting, Organizations and Society, 37 (4), $207-$ 222

Barton, J., \& Mercer, M. (2005). To blame or not to blame: Analysts' reactions to external explanations of poor financial performance. Journal of Accounting and Economics, 39 (3), $509-533$

Biber, D., (1986). Spoken and written textual dimensions in English: resolving the contradictory findings. Language 62 (2), 384-414

Blau, B., DeLisle, J., \& McKay Price, S. (2015). Do sophisticated investors interpret earnings conference call tone differently than investors at large? Evidence from short sales. Journal of 
Corporate Finance, 31, 203-219

Bohner, G., Bless, H., Schwart, N., \& Strack, F. (1988). What triggers causal attributions? The impact of valence and subjective probability. European Journal of Social Psychology, 18 (4), 335-345

Bradshaw, M. (2002). The use of target prices to justify sell-side analysts' stock recommendations. Accounting Horizons, 16 (1), 27-41.

Bradshaw, M. (2011). Analysts' forecasts: What do we know after decades of work? Unpublished working paper, available at: http://papers.ssrn.com/sol3/papers.cfm?abstract_id=1880339 (Accessed 21 December 2015)

Bradshaw, M., Drake, M., Myers, J., \& Myers, L. (2012). A re-examination of analysts' superiority over time-series forecasts of annual earnings. Review of Accounting Studies, 17 (4), 944-968

Bradshaw, M., Richardson, S., \& Sloan, R. (2001). Do analysts and auditors use information in accruals? Journal of Accounting Research, 39 (1), 45-74.

Breton, G., \& Taffler, R. (2001). Accounting information and analyst stock recommendation decisions: a content analysis approach. Accounting and Business Research, 31 (2), 91-101

Brochet, F., Loumioti, M., \& Serafeim, G. (2015) Speaking of the short-term: disclosure horizon and managerial myopia, Review of Accounting Studies, 20 (3), 1122-1163

Brockman, P.,Li, X., \& S. McKay Price. (2015). Difference in conference call tones: managers vs. analysts. Financial Analysts Journal, 71 (4), 24-42

Brown, L., Call, A., Clement, M., \& Sharp, N. (2015). Inside the "black box" of sell-side financial analysts, Journal of Accounting Research 53 (1), 1-47

Brown, L, Caylor, M. (2005). A temporal analysis of quarterly earnings thresholds: propensities, and valuation consequences. The Accounting Review, 80 (2), 423-440

Brown, S., Hillegeist, S., \& Lo. K. (2009). The effect of earnings surprises on information asymmetry. Journal of Accounting and Economics, 47 (3), 208-225

Bushee, B., Gow, I., \& D. Taylor. (2015). Linguistic complexity in firm disclosures: obfuscation or information? Unpublished working paper, available at http://papers.ssrn.com/sol3/Papers.cfm?abstract_id=2375424 (Accessed 21 December 2015)

Chafe, W., \& Tannen, D. (1987). The relation between written and spoken language. Annual Review of Anthropology 16, 383-407

Chen, J., Demers, E., \& Lev, B. (2013). Oh what a beautiful morning! The time of the day effect on the time and market impact of conference calls. Unpublished working paper, available at: http://papers.ssrn.com/sol3/papers.cfm?abstract_id=2186862 (Accessed 21 December 2015) 
Chen, J., Nagar, V., \& Schoenfeld, J., (2015). Information dispersion in financial markets. Unpublished working paper, available at: http://papers.ssrn.com/sol3/papers.cfm?abstract_id=2084488 (Accessed 21 December 2015)

Chen, S., \& Matsumoto. D.A. (2006). Favorable versus unfavourable recommendations: the impact on analyst access to management-provided information. Journal of Accounting Research, 44 (4), 657-689

Chen, X, Cheng. Q., \& Lo, K. (2010). On the relationship between analyst reports and corporate disclosures: exploring the roles of information discovery and interpretation. Journal of Accounting and Economics, 49 (3), 206-226

Clement, M., Hales, J., \& Xue, Y. (2011). Understanding analysts' use of stock returns and other analysts' revisions when forecasting earnings. Journal of Accounting and Economics, 51 (3), 279-299

Cohen, L., Lou, D., \& Malloy, C. (2013). Playing favorites: how firms prevent the revelation of bad news, NBER Working paper

Cowen, A., Groysberg, B., \& Healy, P. (2006). Which types of analyst firms are more optimistic? Journal of Accounting and Economics, 41 (1-2), 119-146

Cox, A. (2009). Investment research fighting its corner. Financial Times. 20.03.2009, p15

Cram, D., Karan, V., \& Stuart, I. (2009). Three threats to validity of choice-based and matchedsample studies in accounting research. Contemporary Accounting Research 26 (2), 477-516

Davis, A., Ge, W. Matsumoto, D., \& Zhang, J. (2015). The effect of manager-specific optimism on the tone of conference calls. Review of Accounting Studies, 20 (2), 639-673

Dechow, P., Hutton, A., \& Sloan, R. (2000). The relation between analysts' forecasts of longterm earnings growth and stock price performance following equity offerings. Contemporary Accounting Research, 17 (1), 1-32.

DeFond, M. L., \& Park, C. W. (1999). The effect of competition on CEO turnover. Journal of Accounting and Economics, 27 (1), 35-56.

De Franco, G., \& Hope, O-K. (2011). Do analysts' notes provide new information? Journal of Accounting, Auditing and Finance, 26 (2), 229-254

Diamond, D., \& Verrecchia, R. (1991) Disclosure, liquidity and the cost of equity capital, Journal of Finance, 46 (4), 1325-1359

Ditto, P., \& Lopez, D. (1992). Motivated scepticism: use of differential decision criteria for preferred and nonpreferred conclusions. Journal of Personality and Social Psychology, 63 (4), $568-584$

Drake, M., \& Myers, L. (2011). Analysts' accrual related over-optimism: do analyst 
characteristics play a role? Review of Accounting Studies, 16 (1), 59-88

Easley, D., \& O’Hara, M. (2004). Information and the cost of capital. Journal of Finance, 59 (4), $1552-1583$

Farrell, K. A., \& Whidbee. D. A. (2003). Impact of firm performance expectations on CEO turnover and replacement decisions. Journal of Accounting and Economics, 36 (1), 165-196.

Feng, M., \& McVay, S. (2010). Analysts' incentives to overweight management guidance when revising their short-term earnings forecasts. The Accounting Review 85 (5), 1617-1646

Financial Times. (2001). Shoot all the analysts. 20.03.2001, p22.

Financial Times. (2008). Titans who were brought to book. 11.03.2008, p2

Fogarty, T., \& Rogers, R. (2005). Financial analysts' reports: an extended institutional theory evaluation. Accounting, Organizations and Society, 30 (4), 331-356

Folkes, V. (1984). Consumer Reactions to Product Failure; An Attributional Approach. Journal of Consumer Research, 10 (4), 398-409

Francis, J., \& Philbrick, D. (1993). Analysts' decisions as products of a multi-task environment. Journal of Accounting Research, 31 (2), 216-230

Frankel, R., Johnson, M., \& Skinner, D. (1999). An empirical examination of conference calls as a voluntary disclosure medium. Journal of Accounting Research, 37 (1), 133-150

Galai, D., \& Masulis, R. (1976). The option pricing model and the risk factor of stock. Journal of Financial Economics, 3 (1), 53-81

Gasparino, C. (2001). Deals \& deal makers: outlook for analysts: skepticism and blame. Wall Street Journal, 13.06.2001.p.C1

Graham, J., Harvey, C., \& Rajgopal, S. (2005). The economic implications of corporate financial reporting. Journal of Accounting and Economics, 40 (1), 3-73

Green, T., Jame, R., Markov, S., \& Subasi, M. (2014). Broker-hosted investor conferences. Journal of Accounting and Economics 58 (1), 142-166

Grene, S. (2009). Sellside research hit by quality concerns. Financial Times, 15.06.2009, p3

Groysberg, B., Healy, P., \& Maber, D. (2011). What drives sell-side analyst compensation at high-status investment banks? Journal of Accounting Research, 49 (4), 969-1000

Gu, Z., Li, Z., \& Yang, Y. (2013). Monitors or predators: the influence of institutional investors on sell- side analysts. The Accounting Review, 88 (1), 137-169

Hardin, J. \& Hilbe, J. (2003). Generalized estimating equations. Chapman \& Hall, Boca Raton, Fla.

Henry, E. \& Leone, E. (2016). Measuring qualitative information in capital markets research: comparison of alternative methodologies to measure disclosure tone. The Accounting Review, 
91(1), 153-178

Hilary, G., \& Hsu, C. (2013). Analyst forecast consistency. Journal of Finance 68(1), 271-297

Hollander, S., Pronk, R., \& Roelofsen, E. (2010) Does silence speak? An empirical analysis of disclosure choices during conference calls. Journal of Accounting Research, 48(5), 531-563

Hovakimian, A., \& Saenyasiri, E. (2010). Conflicts of interest and analyst behavior: evidence from recent changes in regulation Financial Analysts Journal, 66 (4), 96-107

Huang, A., Lehavy. R., Zang, A., \& Zheng, R. (2015), Analyst information discovery and interpretation roles: a topic modeling approach. Unpublished working paper, available at http://papers.ssrn.com/sol3/papers.cfm?abstract_id=2409482 (Accessed 21 December 2015)

Huang, A., Zang, A., \& Zheng, R. (2014). Evidence on the information content of text in analyst reports. The Accounting Review, 89 (6), 2151-2180Hugon, A., \& Muslu, V. (2010). Market demand for conservative analysts, Journal of Accounting and Economics 50 (1), $42-57$

Johnson, W., \& Zhao, R. (2012). Contrarian share price reactions to earnings surprises. Journal of Accounting, Auditing and Finance, 27 (2), 236-266

Kinney, W., Burgstahler, D., \& Martin, R. (2002). Earnings surprise "materiality” as measured by stock returns. Journal of Accounting Research, 40 (5), 1297-1329

Kothari, S., Li, X., \& Short, J. (2009). The effect of disclosures by management, analysts, and business press on cost of capital, return volatility, and analyst forecasts: A study using content analysis. The Accounting Review, 84 (5), 1639-1670

Larcker, D., \& Zakolyukina, A. (2012). Detecting deceptive discussions in conference calls. Journal of Accounting Research, 50 (2), 495- 540

Lau, R., \& Russell, D. (1980). Attributions in the sports pages: A field test of some current hypotheses in attribution research. Journal of Personality and Social Psychology, 39 (1), 2938

Lee, J. (2016). Can investors detect managers' lack of spontaneity? Adherence to pre-determined scripts during earnings conference calls. The Accounting Review 91 (1), 229-250

Liang, K., \& Zeger, S. L. (1986). Longitudinal data analysis using generalized linear models. Biometrika, 73 (1), 13-22

Lin, H., \& McNichols, M. (1998). Underwriting relationships, analysts' earnings forecasts and investment recommendations. Journal of Accounting and Economics, 25 (1), 101-127.

Linell, P. (2005). The Written Language Bias in Linguistics: Its Nature, Origins and Transformations. Routledge: Oxon

Livnat, J., \& Zhang, Y. (2012). Information interpretation or information discovery: which role of analysts do investors value more? Review of Accounting Studies, 17 (3), 612-641 
Loughran, T., \& McDonald, B. (2011). When is a liability not a liability? Textual analysis, dictionaries, and 10-Ks. Journal of Finance, 66 (1), 35-65

Louis, H., Lys, T., \& Sun, A. (2014). Conservatism, analyst ability, and forecast error: evidence on financial statement users' ability to account for conservatism. Unpublished working Paper, available at: http://papers.ssrn.com/sol3/papers.cfm?abstract_id=1031981 (Accessed 21 December 2015)

Lui, D., Markov, S., \& Tamayo, A. (2007). What makes a stock risky? Evidence from sell-side analysts' risk ratings. Journal of Accounting Research, 45 (3), 629-665

Lys, T., \& Sohn, S. (1990). The association between revisions of financial analysts' earnings forecasts and security-price changes. Journal of Accounting and Economics, 13 (4), 341-363

Martinko, M., 1995. Attribution theory: An organizational perspective. CRC Press.

Matsumoto, D., Pronk, M., \& Roelofsen, E. (2011). What makes conference calls useful? The information content of managers' presentations and analysts' discussion sessions. The Accounting Review, 86 (4), 1383-1414

Matsunaga, S., \& Park, C. (2001). The effect of missing a quarterly earnings benchmark on the CEO's annual bonus, The Accounting Review, 76 (3), 313-332

Mayew, W., Sharp, N., \& Venkatachalam, M. (2013). Using earnings conference calls to identify analysts with superior private information. Review of Accounting Studies, 18 (2), $386-413$

Mayew, W., \& Venkatachalam, M. (2012). The power of voice: Managerial affective states and future firm performance. Journal of Finance, 67 (1), 1-43.

McNichols, M., \& O’Brien, P. (1997). Self-selection and analyst coverage. Journal of Accounting Research, 35 (Supplement), 167-199.

Mergenthaler, R., Rajgopal, S., \& Srinivasan, S. (2012). CEO and CFO career penalties to missing quarterly analysts' forecasts. Unpublished working paper, available at http://papers.ssrn.com/sol3/papers.cfm?abstract_id=1152421 (Accessed 21 December 2015)

Milian, J., \& Smith, A. (2015). An investigation of analysts' praise of management during earnings conference calls. Journal of Behavioral Finance, forthcoming

Milne, M., \& Adler, R. (1999). Exploring the reliability of social and environmental disclosures content analysis. Accounting, Auditing and Accountability Journal, 12 (2), 237-256

Ng, J., Verrecchia, R., \& Weber, J. (2009). Firm performance measures and adverse selection. Unpublished working paper

O’Brien, P. (1988). Analysts' forecasts as earnings expectations. Journal of Accounting and Economics, 10 (1), 53-83 
Oliver, R. and Bearden, W. (1985), Disconfirmation processes and consumer evaluations in product usage Journal of Business Research 13, 235-246

Palepu, K., Healy, P., \& Peek, E. (2013) Business Analysis \& Valuation. $3^{\text {rd }}$ edition, Cengage Learning

Penman, S. (2013). Financial Statement Analysis and Security Valuation. $5^{\text {th }}$ edition. McGrawHill, New York

Previts, G., Bricker, R., Robinson, T., \& Young, J. (1994). A content analysis of sell-side financial analyst company reports. Accounting Horizons, 8 (2), 55-70

Price, S. M., Doran, J., Peterson, D., \& Bliss, B. (2012). Earnings conference calls and stock returns: The incremental informativeness of textual tone. Journal of Banking and Finance, 36 (4), 992-1011

Pyszczynski, T., \& Greenberg, J. (1981). Role of disconfirmed expectancies in the instigation of attributional processing. Journal of Personality and Social Psychology, 40 (1), 31-38

Schipper, K. (1991). Analysts' forecasts. Accounting Horizons, 5 (4), 105-121

Schleicher, T., \& Walker, M. (2010). Bias in the tone of forward-looking narratives. Accounting and Business Research, 40(4), 371-390

Soltes, E. (2014). Private interaction between firm management and sell-side analysts, Journal of Accounting Research 52 (1), 245-272

Stickel, S. (1989). The timing of and incentives for annual earnings forecasts near interim earnings announcements. Journal of Accounting and Economics, 11 (2-3), 275-292

Twisk, J. (2004). Longitudinal data analysis: A comparison between generalized estimating equations and random coefficient analysis. European Journal of Epidemiology, 19: 769-776

Walther, B., \& Willis, R. (2013). Do investor expectations affect sell-side analysts' forecast bias and forecast accuracy? Review of Accounting Studies 18 (1), 207-227

Womack, K. (1996). Do brokerage analysts' recommendations have investment value? Journal of Finance, 51 (1), 137-167

Wong, P., \& Weiner, B. (1981). When people ask "why” questions, and the heuristics of attributional search. Journal of Personality and Social Psychology, 40 (4), 650-663

Yezegel, A. (2015). Why do analysts revise their stock recommendations after earnings announcements? Journal of Accounting and Economics, 59 (2-3), 163-1 
Table 1: Descriptive statistics for samples of negative and non-negative earnings quarterly earnings surprises.

\begin{tabular}{|c|c|c|c|c|c|c|c|c|c|c|c|c|}
\hline \multirow[b]{2}{*}{ Variable } & \multicolumn{5}{|c|}{ NES } & \multicolumn{5}{|c|}{ MBE } & \multicolumn{2}{|c|}{$\mathrm{p}$-value for difference: } \\
\hline & Mean & St. dev & Q1 & Med & Q3 & Mean & Std & Q1 & Med & Q3 & T-test & Signed rank \\
\hline \multicolumn{13}{|l|}{ Firm-level characteristics } \\
\hline Market capitalization (\$b) & 19.15 & 37.49 & 3.31 & 7.61 & 19.32 & 17.66 & 35.57 & 2.70 & 7.04 & 17.85 & 0.68 & 0.41 \\
\hline No. analysts & 16.36 & 6.48 & 11.00 & 15.00 & 20.00 & 15.45 & 6.42 & 11.00 & 14.00 & 18.50 & 0.16 & 0.14 \\
\hline Book-to-market & 1.13 & 1.19 & 0.51 & 0.83 & 1.42 & 1.19 & 1.38 & 0.51 & 0.87 & 1.51 & 0.69 & 0.65 \\
\hline \multicolumn{13}{|l|}{ Conference calls } \\
\hline No. analysts & 10.55 & 3.358 & 13.00 & 10.00 & 8.00 & 10.450 & 3.639 & 12.00 & 10.00 & 8.00 & 0.65 & 0.43 \\
\hline No. questions blocks & 24.86 & 8.263 & 30.00 & 24.00 & 19.00 & 24.445 & 7.692 & 30.00 & 24.00 & 19.00 & 0.48 & 0.55 \\
\hline Median block words & 58.93 & 14.36 & 67.00 & 57.00 & 50.00 & 57.515 & 13.036 & 65.50 & 56.00 & 48.00 & 0.22 & 0.24 \\
\hline Sum words & 1599.12 & 566.23 & 1959.00 & 1554.00 & 1167.50 & 1542.20 & 533.228 & 1888.50 & 1503.00 & 1211.50 & 0.12 & 0.19 \\
\hline Days after announcement & 0.13 & 0.33 & 0.00 & 0.00 & 0.00 & 0.15 & 0.43 & 0.00 & 0.00 & 0.00 & 0.52 & 0.75 \\
\hline \multicolumn{13}{|l|}{ Research notes } \\
\hline Report length (words) & 1662.08 & 706.546 & 1959.00 & 1541.25 & 1148.25 & 1636.19 & 704.69 & 1915.75 & 1507.50 & 1210.13 & 0.59 & 0.96 \\
\hline Days after announcement & 0.56 & 0.72 & 0.00 & 0.00 & 1.00 & 0.53 & 0.66 & 0.00 & 0.00 & 1.00 & 0.49 & 0.87 \\
\hline \multicolumn{13}{|l|}{ Earnings announcements } \\
\hline Earnings surprise & -0.003 & 0.007 & -0.002 & -0.001 & -0.000 & 0.003 & 0.007 & 0.001 & 0.001 & 0.003 & 0.01 & 0.01 \\
\hline Abs earnings surprise & 0.003 & 0.007 & 0.001 & 0.001 & 0.002 & 0.003 & 0.007 & 0.001 & 0.001 & 0.003 & 0.69 & 0.78 \\
\hline Forecast dispersion & 0.002 & 0.003 & 0.002 & 0.001 & 0.000 & 0.001 & 0.003 & 0.001 & 0.001 & 0.000 & 0.49 & 0.19 \\
\hline Loss & 0.115 & 0.320 & 0.000 & 0.000 & 0.000 & 0.060 & 0.238 & 0.000 & 0.000 & 0.000 & 0.01 & 0.02 \\
\hline Earnings growth & 0.590 & 0.493 & 1.000 & 1.000 & 0.000 & 0.255 & 0.437 & 1.000 & 0.000 & 0.000 & 0.01 & 0.01 \\
\hline$C A R$ & -0.023 & 0.051 & 0.007 & -0.014 & -0.039 & 0.009 & 0.042 & 0.030 & 0.005 & -0.015 & 0.01 & 0.01 \\
\hline$A b s C A R$ & 0.037 & 0.042 & 0.010 & 0.022 & 0.050 & 0.030 & 0.031 & 0.009 & 0.020 & 0.043 & 0.07 & 0.27 \\
\hline
\end{tabular}

This table reports summary statistics for matched samples of negative quarterly earnings surprises (NES) and quarterly earnings announcements that meet or beat market expectations (MBE). Matching is performed by firm and fiscal quarter such that a negative surprise announced by firm $i$ in quarter $q$ of fiscal year $t$ is paired with a corresponding MBE announced by the same firm for the same quarter in fiscal year $t$-1. The final sample comprises 200 quarterly NES and 200 quarterly MBE observations. For each earnings announcement we collect the corresponding conference call transcript and four research notes published within three days of the earnings announcement. Firm-level variables are defined as follows: Market capitalisation is beginning-ofquarter price multiplied by shares outstanding; no. analysts is the number of analysts on IBES issuing at least one forecast during the quarter; Book-to-market is beginning-of-period book value of shareholders' funds divided by market capitalization. Conference call variables are as follows: no. analysts is the number of equity analysts participating in the conference call; no. question blocks is the number of distinct lines of questioning pursued by each analysts, aggregated over all analysts in the call; Median block words is the number of works for the median question block in the call; Sum words is the total number of works in analysts' questions; Days after announcement is the number of days by which the conference call lags the earnings announcement day. Research notes variables are defined as follows: Report length is the median number of words computed over the four research notes; Days after announcement is the number of days by which the conference call lags the earnings announcement day. Earnings announcement variables are defined as follows: Earnings surprises is the difference between unadjusted IBES actual quarterly earnings and the last unadjusted IBES consensus quarterly earnings forecast prior to the earnings announcement (scaled by lagged price); Abs earnings surprise is the absolute value of earnings surprise; Forecast dispersion is the standard deviation of the last consensus quarterly forecast available on IBES prior to the corresponding quarterly earnings announcement (scaled by lagged share price); Loss is an indicator variable for negative reported earnings; Earnings growth is an indicator variable equal to one if the seasonally adjusted change in quarterly earnings per share is 
negative and zero otherwise; $C A R$ is the two-day cumulative market-adjusted abnormal return ending on the earnings announcement date; $A b s C A R$ is the absolute value of $C A R$. The p-value for difference reported in the final two columns is the two-tailed probability value for paired t- and Wilcoxon signed-ranked tests. 


\section{Table 2: Analyst propensity to probe concerns about performance prospects}

Panel A: Univariate

\begin{tabular}{lccccccc} 
& \multicolumn{3}{c}{ Conference call } & & \multicolumn{3}{c}{ Representative research note } \\
\cline { 2 - 3 } \cline { 7 - 8 } & Mean & Std dev & Median & & Mean & Std dev & Median \\
\hline NES $=0$ & 0.161 & 0.093 & 0.159 & & 0.148 & 0.174 & 0.083 \\
NES $=1$ & 0.201 & 0.114 & 0.192 & & 0.510 & 0.260 & 0.531 \\
p-value for diff. & 0.001 & & 0.001 & & 0.001 & & 0.001
\end{tabular}

Panel B: Generalised estimating equations

\begin{tabular}{lccccc} 
& \multicolumn{2}{c}{ Conference call } & & \multicolumn{2}{c}{ Representative research note } \\
\cline { 2 - 3 } \cline { 5 - 6 } Intercept & Coeff. & $\mathrm{p}$-value & & Coeff. & p-value \\
D_NES & 0.140 & $(0.001)$ & & 0.111 & $(0.002)$ \\
$\mid$ Median FE $\mid$ & 0.034 & $(0.002)$ & & 0.292 & $(0.001)$ \\
Forecastdisp & -0.023 & $(0.360)$ & & 0.112 & $(0.019)$ \\
Loss & 0.000 & $(0.004)$ & & 0.000 & $(0.542)$ \\
AQEPS $<0$ & -0.001 & $(0.953)$ & & -0.026 & $(0.195)$ \\
Log Analyst & 0.018 & $(0.120)$ & & 0.057 & $(0.012)$ \\
Log MV & 0.002 & $(0.055)$ & & 0.002 & $(0.342)$ \\
Otherinfo & 0.703 & $(0.166)$ & & -2.854 & $(0.026)$ \\
CAR & 0.076 & $(0.953)$ & & 9.786 & $(0.005)$ \\
N & -0.068 & $(0.585)$ & & -1.183 & $(0.000)$ \\
\hline
\end{tabular}

This table reports results for univariate (Panel A) and multivariate (Panel B) tests for differences in the extent to which analysts explore weaknesses in firms' performance prospects conditional on the sign of the earnings surprise. Separate results are reported for prospect measures derived from conference calls and research notes. The final row of Panel A reports two-tailed probability values related to paired T-tests (means) and paired Wilcoxon signed rank tests. Summary regression results in Panel B are estimated using Generalised Estimating Equations with an exchangeable correlation structure to account for dependency among matched pairs. All probability values relate to two-tailed tests. Variable definitions are as follows (see Table 3 for further information): $D \_N E S$ is an indicator variable that takes the value of one for negative earnings surprises and zero otherwise; $\mid$ MedianFE $\mid$ is the absolute quarterly earnings surprise; Forecastdisp is the standard deviation of the last consensus quarterly forecast available on IBES prior to the corresponding quarterly earnings announcement (scaled by lagged share price), Loss is an indicator variable for negative reported earnings; $\triangle Q E P S<0$ is an indicator variable taking the value of one if the seasonal change in quarterly earnings is negative and zero otherwise; Log Analyst is the natural logarithm of analysts following; $\log M V$ is the natural logarithm of market capitalisation; Otherinfo is an indicator variable taking the value of one when the firms announce other non-earnings news concurrently with earnings; and CAR is the twoday cumulative abnormal return ending on the earnings announcement date. All p-values relate to two-tailed tests. 
Table 3: Analyst propensity to demonstrate uncertainty

Panel A: Univariate

Conference call: UNCERT Conference call: UNCERT_NEG Representative research note

\begin{tabular}{|c|c|c|c|c|c|c|c|c|c|}
\hline & & & \\
\hline & Mean & Std dev & Median & Mean & Std dev & Median & Mean & Std dev & Median \\
\hline $\mathrm{NES}=0$ & 0.848 & 0.097 & 0.860 & 0.465 & 0.128 & 0.454 & 0.001 & 0.001 & 0.001 \\
\hline $\mathrm{NES}=1$ & 0.861 & 0.083 & 0.870 & 0.490 & 0.134 & 0.500 & 0.003 & 0.018 & 0.001 \\
\hline $\mathrm{p}$-value for diff & 0.109 & & 0.295 & 0.036 & & 0.093 & 0.305 & & 0.522 \\
\hline
\end{tabular}

Panel B: Generalized estimating equations

\begin{tabular}{|c|c|c|c|c|c|c|}
\hline & \multicolumn{2}{|c|}{ Conference call: UNCERT } & \multicolumn{2}{|c|}{ Conference call: UNCERT_NEG } & \multicolumn{2}{|c|}{ Representative research note } \\
\hline & Coeff & p-value & Coeff & p-value & Coeff & p-value \\
\hline Intercept & 0.837 & $(0.001)$ & 0.427 & $(0.001)$ & 0.003 & $(0.016)$ \\
\hline$D \_N E S$ & 0.015 & $(0.089)$ & 0.027 & $(0.040)$ & 0.002 & $(0.289)$ \\
\hline $\mid$ Median FE $\mid$ & -0.001 & $(0.971)$ & 0.032 & $(0.173)$ & 0.000 & $(0.750)$ \\
\hline Forecastdisp & 0.000 & $(0.005)$ & 0.000 & $(0.127)$ & 0.000 & $(0.278)$ \\
\hline Loss & 0.013 & $(0.197)$ & 0.001 & $(0.975)$ & -0.001 & $(0.314)$ \\
\hline$\triangle Q E P S<0$ & 0.001 & $(0.954)$ & 0.011 & $(0.354)$ & -0.002 & $(0.306)$ \\
\hline Log Analyst & -0.001 & $(0.923)$ & -0.000 & $(0.774)$ & 0.000 & $(0.291)$ \\
\hline $\log M V$ & 0.309 & $(0.674)$ & 2.264 & $(0.014)$ & 0.003 & $(0.805)$ \\
\hline Otherinfo & 1.902 & $(0.151)$ & 0.649 & $(0.788)$ & -0.036 & $(0.444)$ \\
\hline$C A R$ & 0.068 & $(0.458)$ & 0.047 & $(0.721)$ & -0.008 & $(0.403)$ \\
\hline $\mathrm{N}$ & 400 & & 400 & & 400 & \\
\hline
\end{tabular}

This table reports results for univariate (Panel A) and multivariate (Panel B) tests for differences in analyst uncertainty conditional on the sign of the earnings surprise. Separate results are reported for uncertainty measures derived from conference calls and research notes. The final row of Panel A reports two-tailed probability values related to paired T-tests (means) and paired Wilcoxon signed rank tests. Summary regression results in Panel B are estimated using Generalized Estimating Equations with an exchangeable correlation structure to account for dependency among matched pairs. All probability values relate to two-tailed tests. Variable definitions are as follows (see Table 3 for further information): $D \_N E S$ is an indicator variable that takes the value of one for negative earnings surprises and zero otherwise; $\mid$ MedianFE $\mid$ is the absolute quarterly earnings surprise; Forecastdisp is the standard deviation of the last consensus quarterly forecast available on IBES prior to the corresponding quarterly earnings announcement (scaled by lagged share price), Loss is an indicator variable for negative reported earnings; $\triangle Q E P S<0$ is an indicator variable taking the value of one if the seasonal change in quarterly earnings is negative and zero otherwise; Log Analyst is the natural logarithm of analysts following; Log $M V$ is the natural logarithm of market capitalisation; Otherinfo is an indicator variable taking the value of one when the firms announce other non-earnings news concurrently with earnings; and CAR is the two-day cumulative abnormal return ending on the earnings announcement date. All p-values relate to two-tailed tests. 
Table 4: Analyst propensity to challenge management

Panel A: Univariate

\begin{tabular}{lccccccc} 
& \multicolumn{3}{c}{ Conference call } & & \multicolumn{3}{c}{ Representative research note } \\
\cline { 2 - 4 } \cline { 6 - 8 } & Mean & Std dev & Median & & Mean & Std dev & Median \\
\hline NES $=0$ & 0.094 & 0.091 & 0.071 & & 0.038 & 0.127 & 0.000 \\
NES $=1$ & 0.142 & 0.118 & 0.120 & & 0.197 & 0.300 & 0.000 \\
p-value for diff & 0.001 & & 0.001 & & 0.001 & & 0.001
\end{tabular}

Panel B: Generalized estimating equations

\begin{tabular}{lccccc} 
& \multicolumn{2}{c}{ Conference call } & & \multicolumn{2}{c}{ Representative research note } \\
\cline { 2 - 3 } \cline { 5 - 6 } Intercept & Coeff & p-value & & Coeff & p-value \\
D_NES & 0.088 & $(0.001)$ & & 0.026 & $(0.470)$ \\
$\mid$ Median $F E \mid$ & 0.035 & $(0.001)$ & & 0.114 & $(0.001)$ \\
Forecastdisp & 0.054 & $(0.057)$ & & 0.047 & $(0.336)$ \\
Loss & 0.000 & $(0.816)$ & & 0.000 & $(0.218)$ \\
AQEPS $<0$ & 0.003 & $(0.820)$ & & 0.026 & $(0.281)$ \\
Log Analyst & 0.009 & $(0.380)$ & & 0.035 & $(0.132)$ \\
Log MV & 0.001 & $(0.503)$ & & 0.000 & $(0.830)$ \\
Otherinfo & 0.069 & $(0.960)$ & & -3.827 & $(0.077)$ \\
CAR & -5.658 & $(0.043)$ & & 5.812 & $(0.208)$ \\
$\mathrm{N}$ & -0.203 & $(0.071)$ & & -0.821 & $(0.012)$ \\
& 400 & & & 400 &
\end{tabular}

This table reports results for univariate (Panel A) and multivariate (Panel B) tests for differences in analysts' propensity to challenge or criticize management conditional on the sign of the earnings surprise. Separate results are reported for challenges to management derived from conference calls and research notes. The final row of Panel A reports two-tailed probability values related to paired T-tests (means) and paired Wilcoxon signed rank tests. Summary regression results in Panel B are estimated using Generalized Estimating Equations with an exchangeable correlation structure to account for dependency among matched pairs. All probability values relate to two-tailed tests. Variable definitions are as follows (see Table 3 for further information): $D \_N E S$ is an indicator variable that takes the value of one for negative earnings surprises and zero otherwise; $\mid$ MedianFE $\mid$ is the absolute quarterly earnings surprise; Forecastdisp is the standard deviation of the last consensus quarterly forecast available on IBES prior to the corresponding quarterly earnings announcement (scaled by lagged share price), Loss is an indicator variable for negative reported earnings; $\triangle Q E P S<0$ is an indicator variable taking the value of one if the seasonal change in quarterly earnings is negative and zero otherwise; Log Analyst is the natural logarithm of analysts following; $\log M V$ is the natural logarithm of market capitalisation; Otherinfo is an indicator variable taking the value of one when the firms announce other non-earnings news concurrently with earnings; and CAR is the two-day cumulative abnormal return ending on the earnings announcement date. 
Table 5: Comparison of prevalence and sensitivity of analysts' attributional search behaviour in conference calls and research notes.

Panel A: Concern about prospects

\begin{tabular}{|c|c|c|c|c|c|c|c|c|c|c|}
\hline \multirow[b]{3}{*}{ Earnings news category } & \multirow{2}{*}{\multicolumn{3}{|c|}{ Representative research note }} & \multirow{2}{*}{\multicolumn{3}{|c|}{ Conference calls }} & \multicolumn{4}{|c|}{ Differences in research notes and conference calls: } \\
\hline & & & & & & & Averag & ferences: & p-values $\mathrm{f}$ & ference in: \\
\hline & Mean & St. dev & Median & Mean & St. dev & Median & Mean & Median & Mean & Median \\
\hline$D \_N E S=0(\mathrm{~N}=200)$ & 0.515 & 0.320 & 0.500 & 0.336 & 0.180 & 0.333 & 0.180 & 0.167 & 0.001 & 0.001 \\
\hline$D \_N E S=1(\mathrm{~N}=200)$ & 0.846 & 0.232 & 1.000 & 0.402 & 0.201 & 0.400 & 0.444 & 0.462 & 0.001 & 0.001 \\
\hline Paired difference & 0.331 & 0.354 & 0.250 & 0.067 & 0.251 & 0.069 & -0.264 & -0.273 & & \\
\hline p-value & 0.001 & & 0.001 & 0.001 & & 0.001 & 0.001 & 0.001 & & \\
\hline
\end{tabular}

Panel B: Challenges to management

\begin{tabular}{|c|c|c|c|c|c|c|c|c|c|c|}
\hline \multirow[b]{3}{*}{ Earnings news category } & \multirow{2}{*}{\multicolumn{3}{|c|}{ Representative research note }} & \multirow{2}{*}{\multicolumn{3}{|c|}{ Conference calls }} & \multicolumn{4}{|c|}{ Differences in research notes and conference calls: } \\
\hline & & & & & & & Averag & ferences: & p-values f & fference in \\
\hline & Mean & St. dev & Median & Mean & St. dev & Median & Mean & Median & Mean & Median \\
\hline$D \_N E S=0(\mathrm{~N}=200)$ & 0.121 & 0.197 & 0.000 & 0.191 & 0.163 & 0.174 & -0.070 & -0.087 & 0.001 & 0.001 \\
\hline$D \_N E S=1(\mathrm{~N}=200)$ & 0.338 & 0.311 & 0.250 & 0.271 & 0.191 & 0.250 & 0.067 & 0.000 & 0.005 & 0.029 \\
\hline Paired difference & 0.216 & 0.313 & 0.250 & 0.080 & 0.2157 & 0.059 & -0.137 & -0.095 & & \\
\hline p-value & 0.001 & & 0.001 & 0.001 & & 0.001 & 0.001 & 0.001 & & \\
\hline
\end{tabular}

This table compares the prevalence and sensitivity of analysts' attributional search behaviour for conference calls and research notes conditional on the sign of the quarterly earnings surprise. $D \_N E S=0$ is the sample of non-negative earnings surprises. $D \_N E S=1$ is the matched sample of negative earnings surprises. Attributional search behaviour is proxied by concern about performance prospects (Panel A) and challenges to management (Panel B). Prevalence for research notes (conference calls) is the fraction of analysts demonstrating at least one instance of attributional search behaviour in their written commentary (questions to management). Sensitivity is the difference in the prevalence of attributional search behaviour between negative earning news and non-negative earnings news. Columns headed "Differences in research notes and conference calls" report average paired differences between research notes and conference calls for a given sign of earnings news, and average difference-in-differences that compare the paired difference across news categories for research notes and conference calls. Probability values refer to parametric (t-) and non-parametric (Wilcoxon signed rank) tests. All probability values relate to two-tailed tests. 